\title{
TASK-3 Two-Pore Domain Potassium Channels Enable Sustained High-Frequency Firing in Cerebellar Granule Neurons
}

\author{
Stephen G. Brickley, ${ }^{1 *}$ M. Isabel Aller, ${ }^{2 \star}$ Cristina Sandu, ${ }^{2}$ Emma L. Veale, ${ }^{1}$ Felicity G. Alder, ${ }^{1}$ Harvinder Sambi, ${ }^{1}$ \\ Alistair Mathie, ${ }^{1}$ and William Wisden ${ }^{2}$ \\ ${ }^{1}$ Biophysics Group, Division of Cell and Molecular Biology, Imperial College London, London SW7 2AZ, United Kingdom, and ${ }^{2}$ Department of Clinical \\ Neurobiology, University of Heidelberg, Heidelberg 69120, Germany
}

\begin{abstract}
The ability of neurons, such as cerebellar granule neurons (CGNs), to fire action potentials (APs) at high frequencies during sustained depolarization is usually explained in relation to the functional properties of voltage-gated ion channels. Two-pore domain potassium $\left(\mathrm{K}_{2 \mathrm{P}}\right)$ channels are considered to simply hyperpolarize the resting membrane potential (RMP) by increasing the potassium permeability of the membrane. However, we find that CGNs lacking the TASK-3 type $\mathrm{K}_{2 \mathrm{P}}$ channel exhibit marked accommodation of action potential firing. The accommodation phenotype was not associated with any change in the functional properties of the underlying voltage-gated sodium channels, nor could it be explained by the more depolarized RMP that resulted from TASK-3 channel deletion. A functional rescue, involving the introduction of a nonlinear leak conductance with a dynamic current clamp, was able to restore wild-type firing properties to adult TASK-3 knock-out CGNs. Thus, in addition to the accepted role of TASK-3 channels in limiting neuronal excitability, by increasing the resting potassium conductance TASK-3 channels also increase excitability by supporting high-frequency firing once AP threshold is reached.
\end{abstract}

Key words: accommodation; action potential; cerebellum; excitability; granule cell; potassium channels

\section{Introduction}

Two-pore domain potassium $\left(\mathrm{K}_{2 \mathrm{P}}\right)$ channels hyperpolarize the resting membrane potential (RMP) by increasing potassium permeability (Millar et al., 2000; Talley et al., 2000), reducing cell excitability by moving the potential away from action potential (AP) threshold (Bean, 2007). The increased input conductance associated with $\mathrm{K}_{2 \mathrm{P}}$ channel opening will further reduce excitability by attenuating excitatory drive (Goldstein et al., 2001; Patel and Honoré, 2001). Many neuromodulators promote closure of $\mathrm{K}_{2 \mathrm{P}}$ channels (Talley et al., 2000; Chemin et al., 2003; Heurteaux

Received March 30, 2007; revised June 12, 2007; accepted July 2, 2007.

This work was supported by The Wellcome Trust (S.G.B.), The Royal Society (S.G.B.), the Medical Research Council (A.M.), German Research Council Deutsche Forschungsgemeinschaft (DFG) WI 1951/1-2 (W.W.), DFG Sonderforschungsbereich 488 "Molecular and Cellular Basis of Neural Development" (W.W.), Volkswagen Stiftung I/78 554 (W.W.), and Fonds der Chemischen Industrie (W.W.). We thank N. P. Franks, D. P. Bright, and S. Trapp for helpful discussions, M. Farrant and R. A. Silver for comments on a previous version of this manuscript, P. Wulfffor advice and input on ES cell culture, F. Zimmermann (IBF, Heidelberg, Germany) for blastocyst injections, I. PreugschatGumprecht (Heidelberg, Germany) for help with genotyping, and P. Kullmann for help modifying G-clamp software. *S.G.B. and M.I.A. contributed equally to data capture.

Correspondence should be addressed to Stephen G. Brickley, Biophysics Group, Division of Cell and Molecular Biology, Imperial College London, London SW7 2AZ, UK. E-mail: s.brickley@imperial.ac.uk.

W. Wisden's present address: Institute of Medical Sciences, University of Aberdeen, Foresterhill, Aberdeen AB25 2ZD, UK.

M. I. Aller's present address: Instituto de Neurociencias de Alicante, Consejo Superior de Investigaciones Cientificas-Universidad Miguel Hernández, Campus de San Juan Apartado 18, 03550 Sant Joan d'Alacant, Spain.

C. Sandu's present address: Institut des Neurosciences Cellulaires et Intégratives, Centre de Neurochimie, 5, rue

Blaise Pascal, F-67084 Strasbourg, France.

D0I:10.1523/JNEUROSCI.1427-07.2007

Copyright $\odot 2007$ Society for Neuroscience $\quad$ 0270-6474/07/279329-12\$15.00/0 et al., 2006; Meuth et al., 2006; Mathie, 2007), and the conventional view would be that $\mathrm{K}_{2 \mathrm{P}}$ closure would increase neuronal excitability.

Here, we explore the possibility that $\mathrm{K}_{2 \mathrm{P}}$ channel opening does more than simply limit excitability. Membrane hyperpolarization could reduce steady-state inactivation of voltage-gated sodium channels (VGSCs), making sustained AP firing more likely once threshold is reached. An increased input conductance will also reduce depolarization block of VGSCs and aid recovery from inactivation because of a faster membrane time constant. In addition, under physiological conditions, the current-voltage relationship of a $\mathrm{K}_{2 \mathrm{P}}$-mediated conductance deviates significantly from a linear ohmic response (Goldman, 1943; Cole, 1949; Hodgkin and Katz, 1949). This open rectification will result in voltage dependence of the input conductance additional to that attributed to conventional voltage-gated potassium channels (Brickley et al., 2001; Cathala et al., 2003). These additional biophysical properties could promote, rather than inhibit, AP firing.

The potassium leak conductance present in adult cerebellar granule neurons (CGNs) correlates with the strong expression of five $\mathrm{K}_{2 \mathrm{P}}$ genes: TWIK-1, TREK-2c, THIK-2, TASK-1, and TASK-3 (Millar et al., 2000; Brickley et al., 2001; Karschin et al., 2001; Rajan et al., 2001; Talley et al., 2001; Gu et al., 2002; Han et al., 2002; Aller et al., 2005). Recombinant TASK-1 and TASK-3 channels combine as homodimers and heterodimers, and it is likely that TASK-1/TASK-3 heterodimers are a prominent combination in adult CGNs (Aller et al., 2005). However, because of dif- 
ferences in single-channel properties (Han et al., 2002; Kang et al., 2004), it is likely that, at physiological pH, TASK-3containing channels (homodimers or heterodimers) will increase potassium permeability to a greater extent than TASK-1 homodimeric channels. We previously showed that genetic deletion of TASK-1 does not alter the leak conductance, the RMP, or AP firing in adult CGNs (Aller et al., 2005). In the current study, we examined the consequence of genetically removing TASK-3 expression on the excitability of adult CGNs. In contrast to the situation for TASK-1 knock-out (KO) neurons (Aller et al., 2005; Meuth et al., 2006), a significant depolarization of the RMP was observed in CGNs lacking TASK-3. In addition, a clear increase in the degree of AP accommodation was apparent both at threshold and suprathreshold levels of depolarization. To directly test the hypothesis that loss of TASK-3 channels was responsible for this phenotype, we reintroduced a nonlinear leak conductance into adult TASK-3 KO CGNs using a dynamic current-clamp procedure. This restored the ability of TASK-3 KO CGNs to fire at high frequencies during sustained depolarization.

\section{Materials and Methods}

Generation of TASK-3 knock-out mice. As deduced by aligning the TASK-3 coding sequences (Chapman et al., 2000; Kim et al., 2000; Rajan et al., 2000; Vega-Saenz De Miera et al., 2001) against the mouse genomic sequence, the mouse TASK-3 gene (alternative gene names, $K_{2 P} 9.1$, $K C N K 9, K T$ 3.2) lies on chromosome 15E1 (gene reference number, ENSMUSG00000036760; see http://www.ensembl.org/Mus_musculus/ geneview?gene $=$ ENSMUSG00000036760) (supplemental Fig. S2A, available at www.jneurosci.org as supplemental material).

We obtained the mouse TASK-3 gene by screening a mouse 129 BAC library (BAC mouse ES release I, BAC-4921, Library Screening Services; Genome Systems, St. Louis, MO) with a $1 \mathrm{~kb}$ intronic probe (derived from the $5^{\prime}$ end of intron 1 in the TASK-3 gene). This intron 1 probe was generated by PCR on C57BL/6 mouse genomic DNA using the following primers: 5' -CCA TCA CTG TCA TCA CAA CTA TCG-3' (sense) and 5'-CTC ACA GAT CCA AAG AGA TGG ACC-3' (antisense). The targeting vector backbone was constructed by placing an $8 \mathrm{~kb}$ EcoRI fragment of the TASK-3 gene, containing exon 1, into the pLitmus38 vector (New England Biolabs, Beverly, MA) (supplemental Fig. S1 A, available at www.jneurosci.org as supplemental material). The Sall site in the pLitmus38 polylinker was first converted to NotI, permitting later linearization of the targeting vector (supplemental Fig. S1 $B$, available at www. jneurosci.org as supplemental material). An 5'-EcoRV-loxP site (5'GATATCCCATAACTTCGTATAGCATACATTATACGAAGTTAT-3') was then inserted into the unique $B c l$ I site, $560 \mathrm{bp}$ upstream of the initiator ATG codon of exon 1 in the TASK-3 gene. The EcoRV site allows detection of homologous recombination. The final targeting vector was obtained by insertion of a $5^{\prime}$-XhoI-frt-neomycin resistance-frt-loxPSalI- $3^{\prime}$ cassette (Cope et al., 2004) into an engineered SalI site, 275 bp downstream of the $3^{\prime}$ end of exon 1 of the TASK-3 gene (note: the Sall site for receiving the neomycin resistance cassette was introduced by first ligating SalI linkers into an unique AfeI site in intron 1) (supplemental Fig. S1 $B$, available at www.jneurosci.org as supplemental material). A plasmid was selected with both loxP sites in the same orientation. The targeting vector was linearized with NotI and electroporated into mouse embryonic stem (ES) cells (strain 129/Sv, RI; gift from G. Schuetz Laboratory, Deutsches Krebsforschungszentrum, Heidelberg, Germany). The cells were grown on mouse fibroblast cells in medium containing G418. Genomic DNA from ES cell colonies was screened by Southern blotting and hybridization; colony genomic DNA was digested with NcoI, and hybridized with a specific $5^{\prime}$ external probe, giving a $5.8 \mathrm{~kb}$ band for the wild-type allele and a $4.2 \mathrm{~kb}$ band for the targeted allele (supplemental Fig. S1 $D, E$, available at www.jneurosci.org as supplemental material); the $5^{\prime}$ external probe was generated by PCR on C57BL/6 mouse tail genomic DNA using the following primers: 5'-CCA TGG CTA GGG ACA GAG AAG ATA-3' (sense) and 5' -TCT CAT TTC CCC TCT CCA GCA GTA-3' (antisense). The presence of the $5^{\prime}$ loxP site was confirmed by digestion with $E c o R V$ and hybridizing with the same 5' external probe, which gives a $15 \mathrm{~kb}$ wild-type band and a $5.6 \mathrm{~kb}$ targeted allele band (supplemental Fig. S1 D, E, available at www.jneurosci.org as supplemental material). We undertook three electroporations and screenings of ES cell colonies: in the first two screens (of 850 colonies in total screened), no correctly targeted colonies were identified; in the third attempt, of 700 colonies screened, one was positive with the $5^{\prime}$ external probe $(\mathrm{NcoI})$ digest and also contained the $5^{\prime}$ loxP site (EcoRV digestion) (supplemental Fig. S1 $D$, available at www.jneurosci.org as supplemental material). Cells from this targeted stem cell colony were injected (by F. Zimmermann, Heidelberg University, Heidelberg, Germany) into C57BL/6 blastocysts; male chimeras were bred with C57BL/6 wild-type mice; germline transmission of the targeted TASK-3 allele was confirmed by Southern blots of tail DNA digested with $\mathrm{Nco}$ I (which marks the neo gene) and EcoRV (which marks the 5' loxP site) respectively, hybridized with the 5' external probe (supplemental Fig. S1 $E$, available at www.jneurosci.org as supplemental material).

The subsequent generations of TASK- 3 knock-out mice have been maintained as heterozygotes on a C57BL/6 background, and can be genotyped by PCR on genomic DNA with primers flanking the $5^{\prime}$ loxP site (supplemental Fig. $S 1 G$, available at www.jneurosci.org as supplemental material), giving a $400 \mathrm{bp}$ band for the knock-out and $350 \mathrm{bp}$ band for the wild type. For PCR genotyping the primers were as follows: $5^{\prime}$-TCTGTCCCGGCTACCGATCCTGC-3' and 5'-TTCCGTGGGCGCAGCGGGTTCCGC-3'. More information on the TASK-3 knock-out construction is given in the supplemental material (available at www.jneurosci.org).

Quantification of $K_{2 P}$ gene expression in wild-type and TASK-3 knockout brains by real-time PCR. Mouse brain $\mathrm{K}_{2 \mathrm{P}}$ and $\mathrm{GABA}_{\mathrm{A}}$ receptor $\alpha 6$ subunit gene expression were assayed by real-time PCR as described by Aller et al. (2005).

In situ hybridization. In situ hybridization with ${ }^{35} \mathrm{~S}$-labeled oligonucleotide probes was as described by Wisden and Morris (1994) and Aller et al. (2005). Nonspecific labeling of the sections was assessed by hybridizing labeled oligonucleotide in the presence of a 100 -fold excess of unlabeled oligonucleotide. Images were generated by exposure to Biomax MR (Kodak, Rochester, NY) X-ray film, and then scanned and processed in Adobe Photoshop. The TASK-1 and TASK-3 oligonucleotides were identical to those used by us previously (Aller et al., 2005).

Recombinant expression. The tsA-201 cells were transiently transfected using the calcium phosphate method. Briefly, 0.5 or $1 \mu \mathrm{g}$ of cDNA expression vector encoding mouse TASK-3 (Aller et al., 2005) was added to each $15 \mathrm{~mm}$ well, and $1 \mu \mathrm{g}$ of a plasmid encoding the cDNA of green fluorescent protein was included to identify cells expressing channels. After a $24 \mathrm{~h}$ incubation period, the cells were rinsed with saline and fresh growth medium was added to the wells. The cells were incubated at $37^{\circ} \mathrm{C}$ with $5 \% \mathrm{CO}_{2}$ for $24-60 \mathrm{~h}$ before whole-cell voltage-clamp electrophysiological recording measurements were made.

Slice preparation. Adult wild-type ( $81 \pm 6 \mathrm{~d}$ of age) and TASK-3 KO mice ( $85 \pm 10 \mathrm{~d}$ of age) were used for preparation of parasagittal cerebellar slices (250 $\mu \mathrm{m}$ thick). Slices were transferred to a recording chamber and constantly perfused $(2 \mathrm{ml} / \mathrm{min})$ with standard recording solution that contained the following (in $\mathrm{mm}$ ): $125 \mathrm{NaCl}, 2.5 \mathrm{KCl}, 1 \mathrm{CaCl}_{2}, 2$ $\mathrm{MgCl}_{2}, 26 \mathrm{NaHCO}_{3}, 1.25 \mathrm{NaH}_{2} \mathrm{PO}_{4}, 25$ glucose, $\mathrm{pH}$ 7.4, when bubbled with $95 \% \mathrm{O}_{2}$ and $5 \% \mathrm{CO}_{2}$. Whole-cell recordings from CGNs were made using either an Axopatch 200A or 700B amplifier (Molecular Devices, Foster City, CA) run via a National Instruments digitization board (PCI6052E; National Instruments, Austin, TX) on a dedicated PC. All experiments were performed at room temperature $\left(22-23^{\circ} \mathrm{C}\right)$ with $1 \mathrm{~mm}$ kynurenic acid and $30 \mu \mathrm{M}$ picrotoxin added to the external solution to block glutamatergic and GABAergic synaptic transmission. The pipette solution contained the following (in $\mathrm{mM}$ ): $120 \mathrm{KCH}_{3} \mathrm{SO}_{4}, 4 \mathrm{NaCl}, 1$ $\mathrm{CaCl}_{2}, 1 \mathrm{MgCl}_{2}, 10$ HEPES, 5 EGTA, $2 \mathrm{Mg}$-ATP, adjusted to $\mathrm{pH} 7.3$ with $\mathrm{KOH}$. Data acquisition and analysis was performed using WINWCP (version 3.3.3) kindly provided by John Dempster (University of Strathclyde, Glasgow, UK).

Recording procedures and analysis. Voltage recordings were passed through a $2 \mathrm{kHz},-3 \mathrm{~dB}$, eight-pole Bessel filter before digitization at a rate of $20 \mathrm{kHz}$. The RMP of CGNs was measured during the first minute of whole-cell recording. AP waveform analysis was performed on the first 
5-10 APs elicited at current injection threshold for each cell. Average waveforms were constructed from these initial APs by aligning on the AP threshold. AP threshold was estimated using phase plane plots (see Fig. $5 B$ ) of the first derivative as a function of voltage, thus enabling a simple estimate of the initial voltage inflection (Bean, 2007). The phase plane plots also enabled a fit-independent method for estimating the maximum rate of rise and fall for the AP upstroke and repolarizing phase. AP width was estimated at the AP half-height, defined as the distance between the AP threshold and the AP overshoot. The accommodation index was calculated during a suprathreshold depolarizing current pulse of $20 \mathrm{pA}$ above threshold. AP frequency was calculated during the first and last $20 \mathrm{~ms}$ epoch of a current pulse lasting either 200 or $300 \mathrm{~ms}$. APs were considered to have failed if their peak amplitude fell $<80 \%$ of the AP peak amplitude recorded at threshold. Current recordings were digitized at $50 \mathrm{kHz}$ when measuring fast transients and $10 \mathrm{kHz}$ for slower conductance changes such as $I_{\mathrm{K}(\mathrm{SO})}$. In all cases, a $2 \mathrm{kHz},-3 \mathrm{~dB}$, eight-pole Bessel filter was applied before digitization. Particular attention was taken to eliminate possible capacitive and resistive artifacts when action potential waveforms were being used to control the command voltage during voltage-clamp experiments. Action potential waveforms were first recorded from a wild-type adult CGN in response to a series of 400 ms suprathreshold depolarizing current injections. These particular recordings were made at a total gain of $50 \mathrm{mV} / \mathrm{mV}$ and were saved onto a DAT recorder at a bandwidth of $50 \mathrm{kHz}$ after being passed through a 5 $\mathrm{kHz},-3 \mathrm{~dB}$, eight-pole Bessel filter. Voltage records could then be played back into the external voltage command of the patch-clamp amplifier. Subsequent voltage-clamp recordings were only used for these experiments if the seal resistance was $>10 \mathrm{G} \Omega$ and the initial series resistance was $<25 \mathrm{M} \Omega$. Eighty percent series resistance compensation was then applied using a lag time of $3 \mu \mathrm{s}$. A series of control experiments were performed on a model cell to ascertain the validity of this approach.

When examining sodium channel activation, a protocol consisting of a $50 \mathrm{~ms}$ conditioning step at $-100 \mathrm{mV}$ was followed by a series of $25 \mathrm{~ms}$ steps from -105 to $+80 \mathrm{mV}$ in $5 \mathrm{mV}$ increments. For inactivation, the initial $100 \mathrm{~ms}$ step was delivered at command potentials ranging from -100 to $-15 \mathrm{mV}$ in $5 \mathrm{mV}$ increments before the voltage was stepped to a test command at $+20 \mathrm{mV}$ for $25 \mathrm{~ms}$. Data from these experiments were converted into conductance plots and fitted with a Boltzmann function $\left(y=y_{\max } /\left\{1+\exp \left[\left(V-V_{0.5}\right) / k\right]\right\}\right)$ to calculate $V_{0.5}$ and $k$ values. When examining the recovery from inactivation, a $50 \mathrm{~ms}$ conditioning step to $-100 \mathrm{mV}$ was followed by a $25 \mathrm{~ms}$ step to $+20 \mathrm{mV}$. The membrane was then returned to $-100 \mathrm{mV}$ for a maximum of $60 \mathrm{~ms}$ in $0.5 \mathrm{~ms}$ increments to allow recovery from inactivation, before the membrane was stepped back to $+20 \mathrm{mV}$ for $25 \mathrm{~ms}$. The recovery from inactivation plots were fitted with exponential functions $\left(I=\left[\mathrm{O} A_{i} \exp \left(-t / \tau_{i}\right)\right]+C\right)$. The protocols used to examine voltage-gated potassium channel properties consisted of a family of $200 \mathrm{~ms}$ duration voltage steps from a control potential of $-70 \mathrm{mV}$ to test voltages ranging from -120 to $+100 \mathrm{mV}$. These experiments were performed in the presence of $500 \mathrm{~nm}$ TTX, and $1 \mathrm{~mm}$ tetraethylammonium (TEA) was applied when the properties of transient A type potassium channels were examined. Once again, data from these experiments were converted into conductance plots and fitted with a Boltzmann function to calculate $V_{0.5}$ and $k$ values. In all experiments, a $1 \mathrm{~s}$ delay was given between each protocol during which the CGN was held at $-70 \mathrm{mV}$. All data fitting was performed in Origin 6.0 (Microcal, Century City, CA). CGN input conductance was measured from a $100 \mathrm{~ms}$ duration $10 \mathrm{mV}$ hyperpolarizing voltage step from which we also calculated the input capacitance. The membrane time constant $\left(\tau_{\mathrm{m}}\right)$ was then calculated from the calculated input conductance and capacitance.

Dynamic current-clamp procedure. The dynamic current clamp was implemented in a Labview 7.2 (National Instruments) software environment following adaptation of the original G-clamp software (Kullmann et al., 2004). A dynamically variable current was injected into the soma of neurons using a patch-clamp amplifier (interfaced to a slave computer via a National Instruments PCI-6052E DAQ board). To make use of the computers full bandwidth, the slave computer was running embedded software controlled by a second master PC via an ethernet connection. The constant field or Goldman-Hodgkin-Katz (GHK) model provides us with a quantitative description of a nonlinear $I-V$ relationship of the type produced by $\mathrm{K}_{2 \mathrm{P}}$ channel populations. From the GHK equation, we know that the current carried by potassium ions is equal to the permeability of that ion multiplied by a nonlinear function of voltage as follows:

$$
I=\frac{P F-V_{m}}{R T}\left(\frac{\left\{c_{i n}-c_{\text {out }} \exp \left(\frac{-V_{m} F}{R T}\right)\right\}}{\left\{1-\exp \left(\frac{-V_{m} F}{R T}\right)\right\}}\right) .
$$

Abbreviations are as follows: $P$, permeability (centimeters per second); $z$, valence of charge; $F$, Faraday's constant (coulombs per mole); $T$, temperature (kelvin); $R$, gas law constant [Joules per (mole kelvin)]; $\left[c_{\text {in }}\right] /\left[c_{\text {out }}\right]$, concentration of ions inside/outside cell. However, we need to describe this relationship in terms of conductance not permeability. Given that the slope conductance $\left(g_{\mathrm{m}}\right)$ at $V \rightarrow \infty$ is given by the following:

$$
g_{m}=\frac{P F^{2} c_{m}}{R T}
$$

substituting $g_{m}$ into the GHK equation,

$$
I=V_{m} \frac{g_{m}}{c_{\text {in }}}\left(\frac{\left\{c_{\text {in }}-c_{\text {out }} \exp \left(\frac{-V_{m} F}{R T}\right)\right\}}{\left\{1-\exp \left(\frac{-V_{m} F}{R T}\right)\right\}}\right) .
$$

The resting conductance of this relationship could then be modified during the experiment to observe the impact of this conductance on the firing properties of CGNs. Reliable performance of the system requires minimal variation, or jitter, from cycle to cycle so that the requested arithmetical operations are achieved during each real-time loop. Operationally, the maximum jitter reported by the system when implementing this simple GHK-type leak was $2 \pm 0.05 \mu$ s, well within the sample interval of $50 \mu$ s used during these experiments.

All statistical tests were performed using STATISTICA 5.1 (StatSoft, Tulsa, OK) and considered significant at $p<0.05$. A Shapiro-Wilk test was used to determine whether measures were normally distributed, and differences between groups were examined using the Student's $t$ test or the Mann-Whitney $U$ test when distributions were not normal. Any possible correlation between variables was examined using a Spearman rank correlation test.

\section{Results}

As seen by in situ hybridization on wild-type adult mouse brains (Fig. 1A), high levels of TASK-3 mRNA were observed in the CGN layer of the cerebellum, the colliculi, hippocampal CA1 and dentate gyrus, anterior dorsal thalamus, the medial habenule, cholinergic cells in the caudate-putamen (Berg and Bayliss, 2007) and many cells in neocortex and olfactory bulb (Aller et al., 2005; Linden et al., 2006). The expression of the TASK-3 gene in mouse brain is identical with that in rat (Karschin et al., 2001; Talley et al., 2001; Vega-Saenz De Miera et al., 2001). On the other hand, although TASK-1 appears to be expressed at slightly higher levels than TASK-3 in CGNs (Fig. 1A,C), in the rest of the brain TASK-1 expression is more limited (Fig. $1 C$ ). Because of a lack of reliable antibodies, it is not yet known whether these mRNA levels correlate with relative TASK-1 and -3 protein levels.

We generated mice with a disabled TASK-3 gene by combined homologous and insertional recombination, so that exon 1 and intron 1 of the gene were crippled (supplemental Fig. S1, available at www.jneurosci.org as supplemental material). The first exon normally encodes the first one-third of the TASK-3 protein up to the first potassium selectivity filter, residues GYG. Both in situ hybridization with a TASK-3 exon 1-specific probe (Fig. $1 B$ ) and real-time PCR (Fig. $1 E$ ) demonstrated that TASK-3 transcripts were absent in the TASK-3 knock-out brain. A commercial polyclonal antibody (anti- $\mathrm{K}_{2 \mathrm{P}} 9.1$; Alomone, Jerusalem, Israel) exhib- 

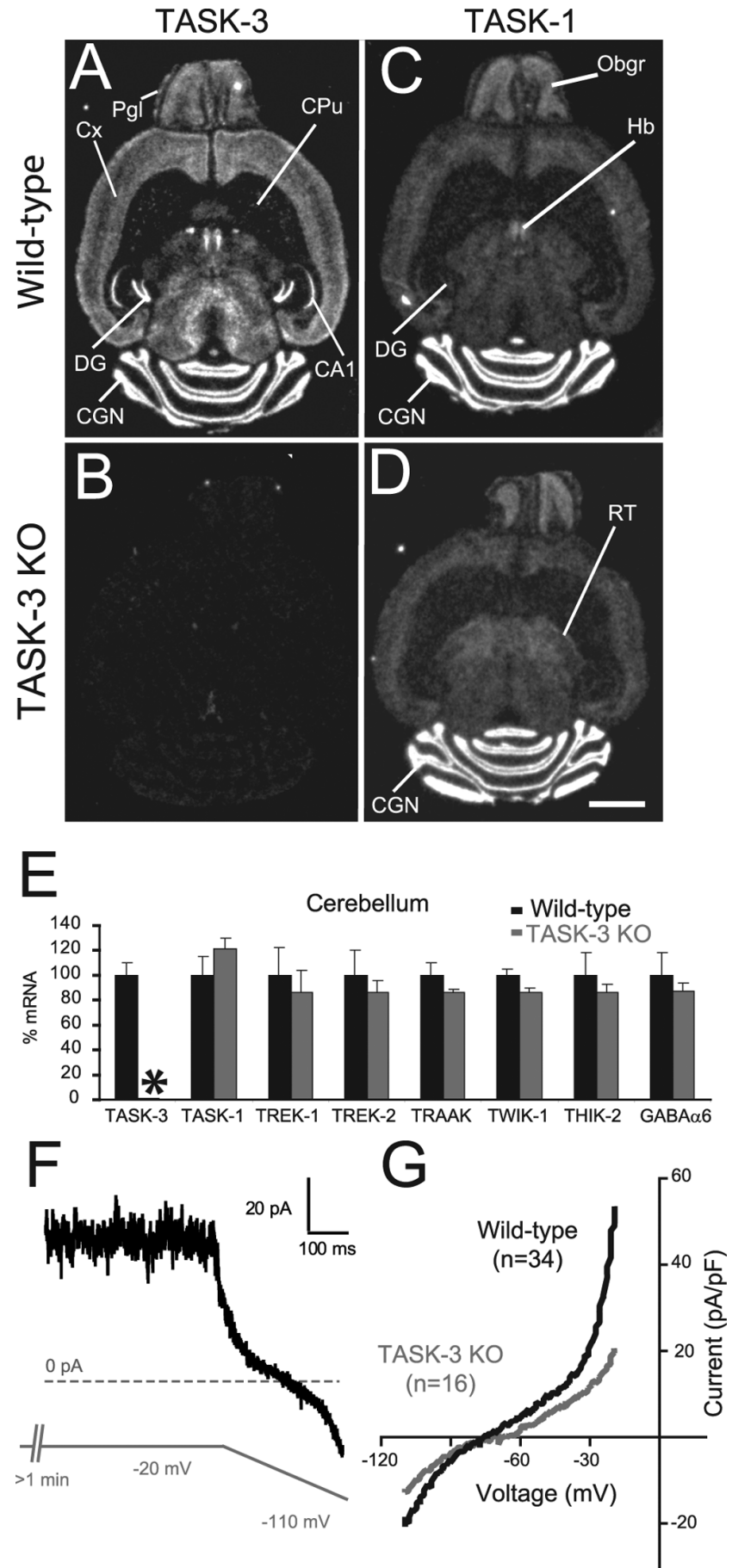

Figure 1. TASK-3 KO mice exhibit a reduced potassium leak conductance. In situ hybridization data from adult wild-type $(\boldsymbol{A}, \boldsymbol{C})$ and TASK-3 KO $(\boldsymbol{B}, \boldsymbol{D})$ mouse brains comparing the distribution of TASK-3 $(\boldsymbol{A}, \boldsymbol{B})$ and TASK-1 mRNA ( $\boldsymbol{C}, \boldsymbol{D})$. TASK-3 mRNA is absent from TASK-3 KO brains with no change in the expression of TASK-1 mRNA. Shown are neocortex $(C \mathrm{C})$, dentate gyrus $(\mathrm{DG})$, caudate putamen $(\mathrm{CPu})$, medial habenule $(\mathrm{Hb})$, periglomerular $(\mathrm{Pgl})$ and granule neurons (Obgr) of the olfactory bulb, reticular nucleus of the thalamus (RT), and (GNs. Scale bar, $2 \mathrm{~mm}$. E, Comparison of mRNA levels between wild-type and TASK-3 $\mathrm{KO}$ cerebellum (real-time PCR) for seven $\mathrm{K}_{2 \mathrm{p}}$ subunits and the $G A B A_{A}$ receptor $\alpha 6$ subunit. The only significant difference between the genotypes was the absence of TASK-3 mRNA (asterisk). A similar pattern was observed for real-time PCR data in the forebrain (data not shown). Error bars indicate SEM. $\boldsymbol{F}, A$ typical voltage-clamp recording illustrating the standing outward potassium current recorded at -20 $\mathrm{mV}$ in a wild-type adult CGN. The command voltage has been maintained at $-20 \mathrm{mV}$ for at least $1 \mathrm{~min}$ before the amplitude of the non-inactivating component of this leak conductance was measured. The voltage was then ramped down to $-110 \mathrm{mV}$ in $800 \mathrm{~ms}$ to construct the currentvoltage plots shown. G, These graphs compare the average current-voltage relationships for 34 wild-type CGNs (black trace) and 16 TASK-3 K0 CGNs (gray trace). ited equally strong staining in wild-type and TASK-3 KO brains (data not shown). By in situ hybridization, TASK-1 mRNA expression was unaltered between wild-type and TASK-3 KO brains (Fig. 1D). The size and gross morphology of the TASK-3 KO brains did not differ from wild-type brains. There was no change in the mRNA levels, measured by real-time PCR, for other $\mathrm{K}_{2 \mathrm{P}}$ channel genes expressed in the TASK-3 KO cerebellum (Fig. 1E) or forebrain (data not shown). Because of the reciprocal relationship between loss of extrasynaptic $\mathrm{GABA}_{\mathrm{A}}$ receptor types ( $\alpha 6$ and $\delta$ subunit-containing) in CGNs and increased TASK-1 and -3 gene expression (Brickley et al., 2001; Aller et al., 2005), we examined $\alpha 6$ gene expression in the cerebellum from TASK-3 knock-outs; but no change in $\alpha 6$ subunit mRNA levels was found (Fig. 1E).

In the laboratory environment, adult TASK-3 KO mice exhibited no obvious health problems, and bred normally as both heterozygotes and homozygotes. No strong behavioral abnormalities were observed and adult TASK-3 KO mice showed no overt neurological symptoms: for example, TASK-3 KO mice exhibited normal motor behavior on the rotarod (A.-M. Linden and E. Korpi, unpublished data). In the current study, TASK-3 KO mice were used to explore how native $\mathrm{K}_{2 \mathrm{P}}$ channels containing the TASK-3 protein influence the biophysical properties of CGNs. As will become apparent, it is possible to describe a clear "electrophysiological deficit” for TASK-3 KO CGNs, which was presumably compensated for at the neural network/whole animal level (see Discussion).

Loss of TASK-3 channels reduces the potassium permeability of adult CGNs

In the acute slice preparation, the steady-state outward current (Fig. $1 F$ ), recorded at $-20 \mathrm{mV}$, was significantly reduced in adult TASK-3 KO CGNs $(41.4 \pm 2.3 \mathrm{pA} / \mathrm{pF}, n=55$ in the wild type; vs $22.9 \pm 2.9 \mathrm{pA} / \mathrm{pF}, n=16$ in TASK-3 KO). The outward rectification of the potassium leak current is characteristic of a $\mathrm{K}_{2 \mathrm{P}}$ channel population recorded with asymmetrical potassium ion concentrations, and the magnitude of this conductance across the entire voltage range examined is clearly reduced in the TASK-3 KO CGNs (Fig. 1G). The ensuing reduction in the potassium permeability of the membrane resulted in a significant $\sim 10 \mathrm{mV}$ depolarization of the RMP from $-80.3 \pm 1.1 \mathrm{mV}(n=$ $55)$ in wild type to $-70.9 \pm 1.8 \mathrm{mV}(n=27)$ in TASK-3 KO CGNs. This is consistent with a movement away from the potassium equilibrium potential $(-104 \mathrm{mV})$ when TASK-3 channels are removed from CGNs. Indeed, it can be seen in Figure $1 G$ that the intersection between the wild-type and TASK-3 KO average $I-V$ relationships is close to this potassium equilibrium potential. A reduced leak conductance was not observed in TASK-1 knockout mice, and, therefore, we observed no change in the RMP (Aller et al., 2005). This highlights the relative importance of TASK-3-containing $\mathrm{K}_{2 \mathrm{P}}$ channels in maintaining the hyperpolarized RMP of adult CGNs. A reduced potassium leak conductance in TASK-3 KO CGNs (compared with wild type) was also apparent in the presence of TTX, TEA, and 4-AP (see Fig. 7A). The non-inactivating property of the $\mathrm{K}_{2 \mathrm{P}}$ leak conductance allowed us to quantify the reduction in this conductance in the absence of potassium channel blockers. This was fortunate given that pharmacological isolation of the potassium leak conductance is complicated by the fact that recombinant TASK channels do exhibit some TEA sensitivity $\left(\mathrm{IC}_{50} \sim 10 \mathrm{~mm}\right.$ ) (S. G. Brickley and A. Mathie, unpublished observations). 


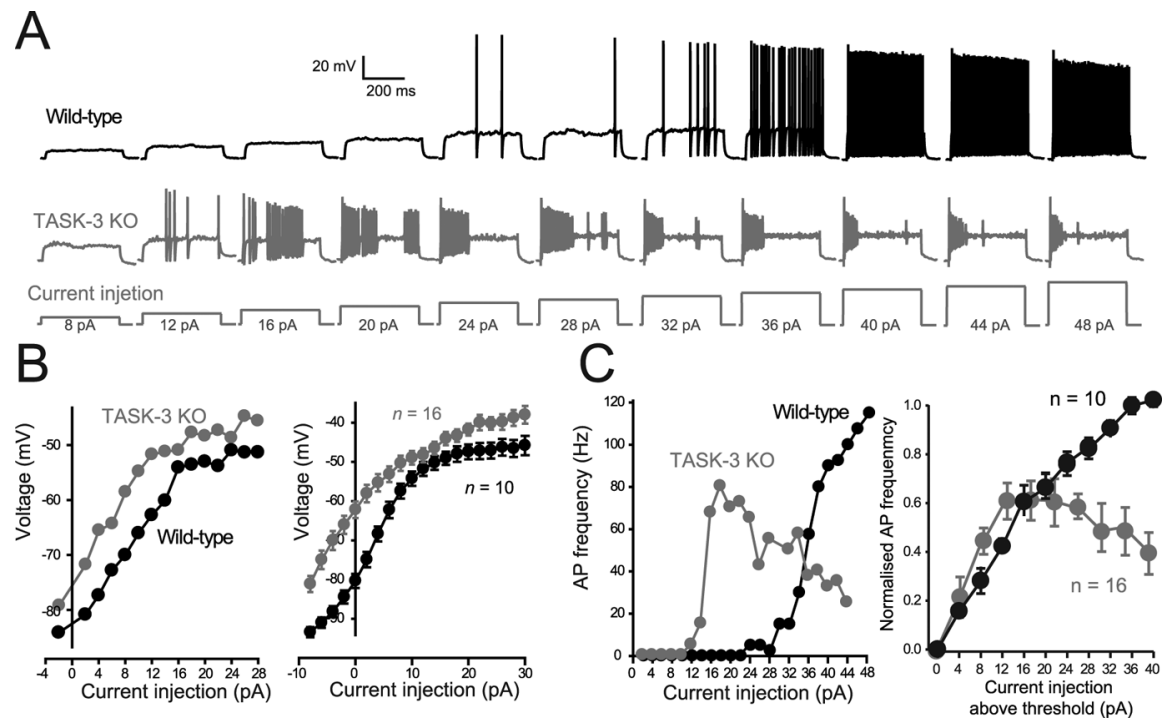

Figure 2. Alterations in CGN excitability associated with the TASK-3 KO. A, Voltage recordings from adult CGNs during current injection experiments comparing a wild type (black trace) and a TASK-3 KO (gray trace). The current injection protocol for both experiments is illustrated in the bottom trace. In the two examples illustrated, APs are elicited with a smaller current injection in the TASK-3 KO compared with the wild type. However, once AP threshold is passed, the TASK-3 KO CGN accommodates more profoundly than the wild-type CGN. At suprathreshold intensities, complete AP failure is observed by the end of a 300 ms current pulse in this TASK-3 KO CGN. In contrast, at the range of current injections examined, no such behavior was observed in the wild-type CGN. B, Subthreshold membrane voltage responses for wild-type and TASK-3 KO CGNs during current injection experiments. The left panel illustrates the voltage response during the experiments shown in $\boldsymbol{A}$. The right panel plots the average response from 10 wild-type and 16 TASK-3 KO CGNs. C, AP frequency during current injections for the cells shown in $\boldsymbol{A}$ (left panel) and average responses across 10 wild-type and 16 TASK-3 KO CGNs (right panel). For the average responses, the current injection has been expressed relative to the threshold current value, and the AP frequency is normalized to the maximum response. Error bars indicate SEM.

\section{AP accommodation is more pronounced in TASK-3 KO CGNs}

As shown in Figure $2 A$, the current required to reach AP threshold was clearly reduced in TASK-3 KO CGNs, reflecting the more depolarized RMP and decreased input conductance of these cells. In the examples shown, only $12 \mathrm{pA}$ of current was required to reach AP threshold in the TASK-3 KO compared with $24 \mathrm{pA}$ in the wild-type CGN. The AP height recorded was also clearly reduced in the TASK-3 KO example (see below). The increased excitability of TASK-3 KO CGNs was further apparent in the subthreshold membrane behavior illustrated in Figure $2 B$, both for the individual examples and the CGN populations as a whole (Fig. 2B). Once AP threshold was reached, high-frequency AP firing was still observed in TASK-3 KO adult CGNs. The most striking phenotype observed in TASK-3 KO CGNs was the marked AP accommodation during suprathreshold current injections. In all TASK-3 KO CGNs examined, the AP peak amplitude was heavily attenuated during sustained depolarization, and in 17 of 27 CGNs this resulted in complete AP failure by the end of a suprathreshold depolarizing current pulse. Correlated with the reduction in AP height, it is also clear that in TASK-3 KO CGNs the afterhyperpolarization (AHP) is also reduced in magnitude during suprathreshold depolarization (Figs. 2A, 3C, 4A). Therefore, during sustained depolarization, the smaller AHP will hinder recovery of VGSCs from inactivation, perhaps trapping channels in a slow inactivated state. The difference in the inputoutput curves constructed from the wild-type and TASK-3 KO data sets is explained by the altered level of accommodation (Fig. $2 C)$. In the TASK-3 KO data set, accommodation at suprathreshold depolarization results in a decline in AP instantaneous fre- quency. No decline in output frequency was observed in the wild-type CGN population at the current intensities examined.

The level of accommodation was quantified both at threshold depolarizations and during suprathreshold current injections. When examining AP accommodation at threshold, AP properties were compared at current injections that elicited the first burst of three or more spikes. In this way, the degree of AP accommodation could be quantified at similar membrane voltages $(-46.1 \pm 1.0 \mathrm{mV}, n=44$ in wildtype; vs $-44.9 \pm 0.9 \mathrm{mV}, n=27$ in TASK-3 KO CGNs). As shown in Figure $3 A$, the degree of AP accommodation at threshold depolarizations was greater in TASK-3 KO CGNs (Fig. 3B). In wild-type CGNs, no change in AP height was observed during the first three spikes with initial average amplitudes of $80.8 \pm 1.8$ $\mathrm{mV}$ and final amplitudes of $79.2 \pm 1.8 \mathrm{mV}$. In contrast, the average AP height measured in the TASK-3 KO CGNs reduced significantly from $55.4 \pm 2.8$ to $49.9 \pm 3.5$ $\mathrm{mV}$. At suprathreshold depolarizations, the AP frequency was compared during the first and last $20 \mathrm{~ms}$ epoch of the current pulse (30 pA above threshold). As expected from previous studies (D'Angelo et al., 1998, 2001; Brickley et al., 2001; Chadderton et al., 2004), the resulting accommodation index (ratio of the instantaneous frequency recorded at the end and start of a suprathreshold current pulse) in wild-type CGNs was high $(0.97 \pm 0.05 ; n=18)$, and consistent with our previous findings (Aller et al., 2005), this measure was no different in TASK-1 KO CGNs $(0.94 \pm 0.07 ; n=$ 9) (Fig. 3D). However, in TASK-3 KO CGNs, this measure had significantly reduced to $0.20 \pm 0.06(n=26)$.

\section{Depolarized RMP is not responsible for increased accommodation in TASK-3 KO CGNs}

VGSC availability for activation will be influenced by the initial RMP, and this could influence the degree of accommodation observed in TASK-3 KO CGNs. As seen from Figure 3D, there was considerable overlap in the recorded RMPs of wild-type and TASK-3 KO CGNs. However, TASK-3 KO CGNs with relatively hyperpolarized RMPs still exhibit marked accommodation; conversely, accommodation was not observed in the more depolarized wild-type CGNs. To directly examine how AP generation was influenced by the RMP of CGNs, we injected steady-state current to impose an RMP on wild-type and TASK-3 KO CGNs. It is unclear to what extent this procedure would uniformly influence the entire CGN membrane, but, as shown in Figure 4, A and $C$, in TASK-3 KO CGNs, hyperpolarizing the RMP did not prevent accommodation $(n=7)$. Conversely, in wild-type CGNs, accommodation was only observed at imposed RMPs more depolarized than $-60 \mathrm{mV}$ (Fig. $4 B, D$ ). In the wild-type example shown, a CGN was chosen that exhibited a similar RMP to the TASK-3 KO CGN (around $-70 \mathrm{mV}$ ). The same current injection that resulted in AP accommodation in the TASK-3 KO CGN elicited continuous AP firing in this wild-type example. Steady-state depolarization of this wild-type CGN to around -40 
$\mathrm{mV}$ resulted in tonic AP firing, and accommodation was superimposed on subsequent current injection pulses. Therefore, it is possible to induce AP accommodation in wild-type CGNs by steady-state depolarization, but this only occurred at voltages near AP threshold. Collectively, these data suggest that steady-state inactivation of VGSCs was not responsible for the accommodation observed in the TASK-3 KO CGNs.

\section{Changes in action potential shape in TASK-3 KO adult CGNs}

As shown in Figure $5 A$, the AP threshold in TASK-3 KO cells was similar to that we previously reported for adult CGNs (Cathala et al., 2003) and no different to that calculated for the wild type. In the current study, we used phase plane plots (Fig. $5 B$ ) to estimate the AP threshold in wild-type $(-39.4 \pm 1.1 \mathrm{mV} ; n=49)$ and TASK-3 KO $(-40.6 \pm 0.8 \mathrm{mV} ; n=29)$ adult CGNs. As shown in Figure $5 C$, the AP height [calculated according to Bean (2007)] had significantly reduced from $106.4 \pm 1.6 \mathrm{mV}(n=49)$ in the wild type to $84.3 \pm 3.3 \mathrm{mV}(n=29)$ in TASK-3 KO CGNs reflecting a reduction in the AP overshoot $(36.5 \pm 1.5 \mathrm{mV}$ in wild type vs $14.2 \pm 2.7 \mathrm{mV}$ in the TASK-3 KO) with little change in the AHP $(-69.9 \pm 0.9 \mathrm{mV}$ in wild type vs $-70.0 \pm 1.0 \mathrm{mV}$ in the TASK-3 KO). Gaussian fits to histograms constructed from AP half-width estimates (Fig. 5D) indicated a significantly broader AP in TASK-3 KO adult CGNs, with an average half-width of $624 \pm 61 \mu$ s in the TASK-3 KO compared with $435 \pm 21 \mu$ s in wild-type CGNs. This broader AP reflected a significantly slower rate of AP rise during the upstroke: $250.4 \pm 10.0 \mathrm{mV} \cdot \mathrm{ms}^{-1}$ in wild type compared with only $159.9 \pm 18.1 \mathrm{mV} \cdot \mathrm{ms}^{-1}$ in the TASK-3 KO. The repolarizing phase of the AP was also slower: $-220.4 \pm 9.5 \mathrm{mV} \cdot \mathrm{ms}^{-1}$ in wild-type compared with $-166.3 \pm$ $21.2 \mathrm{mV} \cdot \mathrm{ms}^{-1}$ in TASK-3 $\mathrm{KO}$ adult CGNs. From these data, it is clear that the rising phase of the AP is more affected in the TASK-3 KO than the falling phase (Fig. $5 E$ ). This is to be expected, given that voltage-gated potassium channels do not contribute to the rising phase of the AP (Bean, 2007). In contrast, $\mathrm{K}_{2 \mathrm{P}}$ channel opening is expected to influence the input conductance during the AP upstroke in a manner not predicted of standard voltage-gated potassium channels. During the repolarizing phase of the AP, voltage-gated potassium channels will make a significant contribution to the membrane time constant, therefore minimizing the impact of the reduced $\mathrm{K}_{2 \mathrm{P}}$-mediated leak conductance in TASK-3 KO adult CGNs.

We also examined AP broadening during repetitive firing in the two strains. APs generated from adult CGNs during threshold current injection (Fig. $5 F$ ) were analyzed in a total of 43 wild-type and 26 TASK-3 KO CGNs. As shown in Figure 5G, in wild-type CGNs, there was little change in AP width at any instantaneous frequency, but in TASK-3 KO recordings the AP width was significantly broadened at all frequencies. It was also clear that the average instantaneous frequency had significantly increased from $46 \pm 4.5 \mathrm{~Hz}(n=422)$ in wild-type to $84.5 \pm 3.8 \mathrm{~Hz}(n=277)$ in TASK-3 KO CGNs. The mechanisms responsible for this apparent increase in instantaneous AP frequency in the TASK-3 KO are unclear at present and require additional examination. However, a reduction in the $\mathrm{K}_{2 \mathrm{P}}$-mediated leak conductance can explain the spike broadening apparent at all these instantaneous frequencies, because a slower rising AP will occur regardless of instantaneous frequency in the TASK-3 KO CGNs.

\section{Changes in action potential shape cannot be explained by differences in voltage-gated channels}

It could also be that the functional properties of the underlying voltage-gated channels have been altered in the TASK-3 KO mice. Conductance changes resulting from VGSC activation were directly examined in adult CGNs using standard voltage-clamp protocols (Fig. 6). These experiments indicated no significant difference in the properties of VGSCs when comparing wild-type and TASK-3 KO adult CGNs. For example, the peak sodium conductance $\left(\mathrm{Na}_{\mathrm{T}}\right)$ in wild-type CGNs was $15.9 \pm 3.3 \mathrm{nS}(n=6)$ compared with $14.5 \pm 2.2 \mathrm{nS}(n=6)$ in TASK-3 KO CGNs. As shown in Figure 6, $A$ and $B$, the $10-90 \%$ rise time of the peak sodium conductance measured after a step from -100 to $0 \mathrm{mV}$ was also not altered in the TASK-3 KO adult CGNs (180 $\pm 20 \mu \mathrm{s}$, 

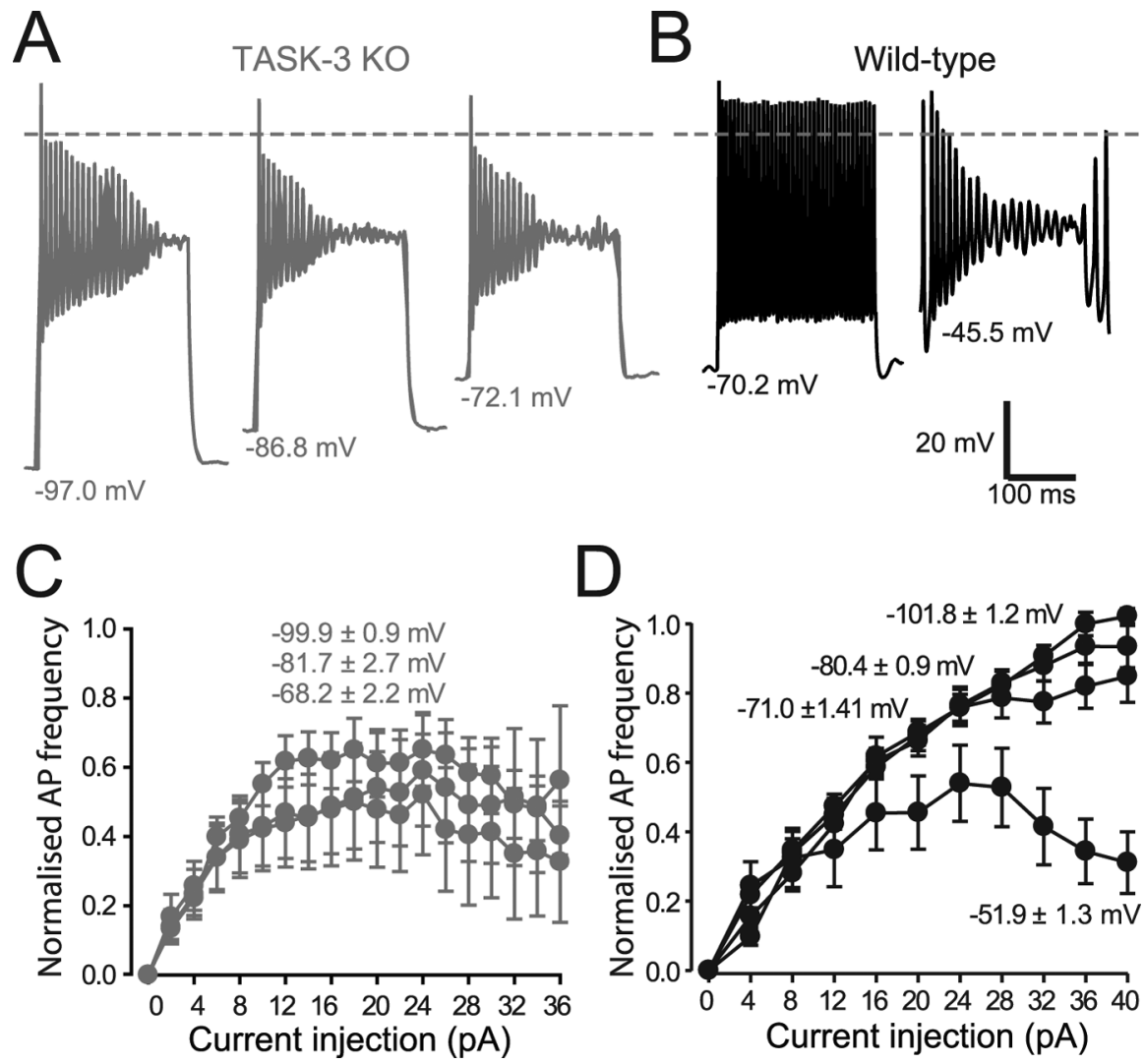

Figure 4. AP accommodation in TASK-3 KO CGNs is not attributable to the depolarized RMP of TASK-3 KO CGNs. $\boldsymbol{A}$, Example of voltage responses from an adult CGN recorded from a TASK- $3 \mathrm{KO}$ mouse that exhibits considerable AP accommodation at different imposed RMPs. B, Example of a wild-type CGN that only exhibits AP accommodation at depolarized potentials more positive than $-50 \mathrm{mV}$. C, Quantification of the relationship between RMP and the normalized AP frequency in TASK-3 KO adult CGNs. At all imposed RMPs the output of the neurons declines at high stimulus intensities because of the accommodation phenotype. $\boldsymbol{D}$ Quantification of the relationship between RMP and the normalized AP frequency in wild-type adult CGNs. AP accommodation only reduces the AP frequency at imposed RMPs more depolarized than $-50 \mathrm{mV}$. Error bars indicate SEM.

$n=6$ in wild type; vs $192 \pm 11 \mu \mathrm{s}, n=6$ in TASK-3 KO). Furthermore, the midpoint for activation $(-45.9 \pm 1.8$ vs $-46.4 \pm 1.8 \mathrm{mV})$ and inactivation $(-44.8 \pm 1.4 \mathrm{vs}-45.6 \pm 2.7$ $\mathrm{mV}$ ) for $\mathrm{Na}_{\mathrm{T}}$-type conductance were no different as was the time course for recovery from inactivation $(1.7 \pm 0.5 \mathrm{vs} 1.5 \pm 0.4 \mathrm{~ms})$. These data would indicate that slowing of the AP upstroke is not attributable to changes in VGSCs but reflects the slower membrane time constant that would result from a reduction in the CGN input conductance on removal of a $\mathrm{K}_{2 \mathrm{P}}$-mediated leak conductance.

In the presence of $500 \mathrm{~nm}$ TTX, voltage-step protocols were also used to elicit the delayed rectifier type conductance $\left(\mathrm{K}_{\mathrm{v}}\right)$ and the transient A-type potassium conductance $\left(\mathrm{K}_{\mathrm{A}}\right)$ in adult CGNs. As shown in Figure $6 E$, the $\mathrm{K}_{\mathrm{A}}$-type conductance was isolated using $1 \mathrm{~mm}$ TEA and the $\mathrm{K}_{2 \mathrm{P}}$ conductance was estimated in the presence of TTX, TEA, and 4-AP as illustrated in Figure 7A. The $\mathrm{K}_{\mathrm{V}}$-like conductance was estimated from the steady-state outward current elicited during voltage-step protocols once the contribution from the TEA-insensitive steady-state component $\left(\mathrm{K}_{2 \mathrm{P}}\right.$ conductance) was subtracted. For the $\mathrm{K}_{\mathrm{V}}$-like conductance (Fig. $6 D)$, the steady-state outward current measured during voltagestep protocols exhibited a similar midpoint for activation in wild type $(10.5 \pm 4.3 \mathrm{mV} ; n=18)$ and TASK-3 KO $(11.0 \pm 3.0 \mathrm{mV}$; $n=18)$. The maximum conductance of this steady-state component was not altered in TASK-3 KO CGNS (12.1 $\pm 1.7 \mathrm{nS}$ in wild type vs $11.2 \pm 0.5 \mathrm{nS}$ in TASK-3 KO). The peak of the transient
$\mathrm{K}_{\mathrm{A}}$-type conductance was then examined in the presence of $1 \mathrm{~mm}$ TEA (Fig. $6 E$ ), and there was no significant difference in the maximum conductance $(7.3 \pm 1.7 \mathrm{nS}, n=$ 3 in wild-type; vs $7.4 \pm 2.0 \mathrm{nS}, n=5$ in TASK-3 KO CGNs), or the midpoint for activation $(6.7 \pm 9.8 \mathrm{mV}$ compared with $5.6 \pm 3.5 \mathrm{mV})$. Next, we compared the $\mathrm{Na}_{\mathrm{T}}, \mathrm{K}_{\mathrm{V}}, \mathrm{K}_{\mathrm{A}}$, and $\mathrm{K}_{2 \mathrm{P}}$ conductance present at $0 \mathrm{mV}$ (Fig. $6 F, G)$ using the average activation curves shown in Figure 6, $C-E$, and the open rectification fits of the TEAinsensitive conductance shown in Figure $7 A$. From this analysis, we would predict that during the repolarizing phase of the AP the $\mathrm{K}_{\mathrm{V}^{-}}$and $\mathrm{K}_{\mathrm{A}}$-type conductance will contribute the largest proportion of the total potassium conductance. However, during the AP upstroke, the $\mathrm{K}_{2 \mathrm{P}}$ component is the only potassium conductance active, and, as discussed previously, this could explain why we see a larger change in the maximum rate of rise in the TASK-3 KO data set.

\section{TASK-3 channels contribute to excitability changes during action potential generation}

To directly examine the contribution a TASK-3 conductance makes to the input conductance during AP generation, we performed AP clamp experiments during which the command voltage was controlled by previously recorded AP waveforms (Fig. 7A). In addition to the glutamate and $\mathrm{GABA}_{\mathrm{A}}$ receptor antagonists, these experiments were performed in the presence of $10 \mathrm{~mm}$ TEA, $5 \mathrm{~mm} 4$-AP, and $500 \mathrm{~nm}$ TTX. Figure 7A shows that, during high-frequency firing, the input conductance contains a voltage-dependent component involving rapid activation/deactivation. The hysteresis observed in the wild-type CGN current-voltage behavior was not evident in TASK-3 KO CGNs. Therefore, the input conductance at $-20 \mathrm{mV}$ was significantly reduced from $5.0 \pm 0.5 \mathrm{nS}(n=34)$ in the wild-type to $3.3 \pm 0.3$ $\mathrm{nS}$ in the TASK-3 KO CGNs $(n=16)$. The very fast activation/ deactivation kinetics are reminiscent of $\mathrm{K}_{\mathrm{V}} 3$ channels (Rudy and McBain, 2001), but $K_{\mathrm{V}} 3$ channels have very positive activation thresholds with $V_{0.5}$ for activation of +10 to $+20 \mathrm{mV}$ (for review, see Rudy and McBain, 2001) and, in any case, would be completely blocked during these experiments (see above). Therefore, we studied recombinant mouse TASK-3 channels to establish whether their behavior could indeed explain these voltage properties seen in native CGN membranes. Mouse TASK-3 channels exhibited similar voltage-dependent activation/deactivation to wild-type CGNs when the command voltage was controlled by AP waveforms (Fig. 7B). The hysteresis that characterized wildtype CGN current-voltage behavior was also observed in recombinant TASK-3 channels. Therefore, the voltage dependence of TASK-3 channels contributes to the increased input conductance of adult wild-type CGNs observed in our experiments. Previous studies have shown fast activation kinetics for TASK-3 channels (time constant, $\sim 2-10 \mathrm{~ms}$ ) (Rajan et al., 2000; Meadows and Randall, 2001), with an apparently instantaneous deactivation of 
TASK-3 that could explain the hysteresis loop signature. The impact of TASK-3 channel expression on the voltage dependence of the input conductance is further illustrated by comparing the CGN membrane time constant $\left(\tau_{\mathrm{m}}\right)$ at specific membrane voltages. In wild-type CGNs, the $\tau_{\mathrm{m}}$ was $7.6 \pm 1.2 \mathrm{~ms}(n=14)$ at a holding potential of $-70 \mathrm{mV}$, but when the membrane was depolarized to $-20 \mathrm{mV}$ the input conductance increased, resulting in a $\tau_{\mathrm{m}}$ of $0.5 \pm 0.1 \mathrm{~ms}$. This effect was significantly attenuated in TASK-3 KO CGNs $(n=16)$ and the $\tau_{\mathrm{m}}$ was slower both at $-70 \mathrm{mV}\left(\tau_{\mathrm{m}}=9.4 \pm 0.01 \mathrm{~ms}\right)$ and -20 $\mathrm{mV}(1.0 \pm 0.1 \mathrm{~ms})$.

Action potential accommodation in adult CGN TASK-3 KOs can be rescued by a nonlinear potassium

leak conductance

TASK-3 gene expression in wild-type CGNs increases throughout development (Zanzouri et al., 2006), but TASK-3 KO CGNs develop with no TASK-3 protein. To rule out the possibility that the electrophysiological mutant phenotype we have described in adult TASK-3 KO CGNs had a developmental origin involving some form of compensation, and to further highlight the role of TASK-3 channels in influencing AP firing, we restored to adult TASK-3 KO CGNs the nonlinear behavior of the input conductance using a dynamic current-clamp approach (Kullmann et al., 2004; Akemann and Knöpfel, 2006). The firing properties of TASK-3 KO CGNs were then examined in the presence of a nonlinear leak conductance. The nonlinear conductance was implemented using the Goldman-Hodgkin-Katz equation with a limiting conductance of $5 \mathrm{nS}$ to approximate the input conductance of wildtype CGNs during AP firing (Fig. 7A). A significant hyperpolarization of $18.1 \pm 4.4$ $\mathrm{mV}(n=7)$ was observed in response to the $5 \mathrm{nS}$ nonlinear potassium-like leak, and therefore, the current required to reach AP threshold was significantly increased from $23.4 \pm 2.5$ to $28.3 \pm 3.1 \mathrm{pA}$. As shown in Figure $8 \mathrm{~A}$, at threshold depolarizations the degree of AP accommodation was modest (height of the third AP was reduced by $5.4 \pm$ $2.8 \%$ ), and in all CGNs examined this accommodation phenotype was no longer apparent in the presence of a $5 \mathrm{nS}$ nonlinear leak (Fig. $8 \mathrm{~B}$ ). Addition of this nonlinear leak conductance in TASK-3 KOs also resulted in a significant increase in the AP height and a reduction in the AP width (Fig. 8C). Five of the seven CGNs used in these experiments exhibited complete AP failure by the end of a $200 \mathrm{~ms}$ suprathreshold depolarization, and all CGNs exhibited accommodation (accommodation index, $0.19 \pm$ $0.12 ; n=7)$. However, in the presence of a $5 \mathrm{nS}$ nonlinear leak conductance, the ability of TASK-3 KO CGNs to fire APs at high
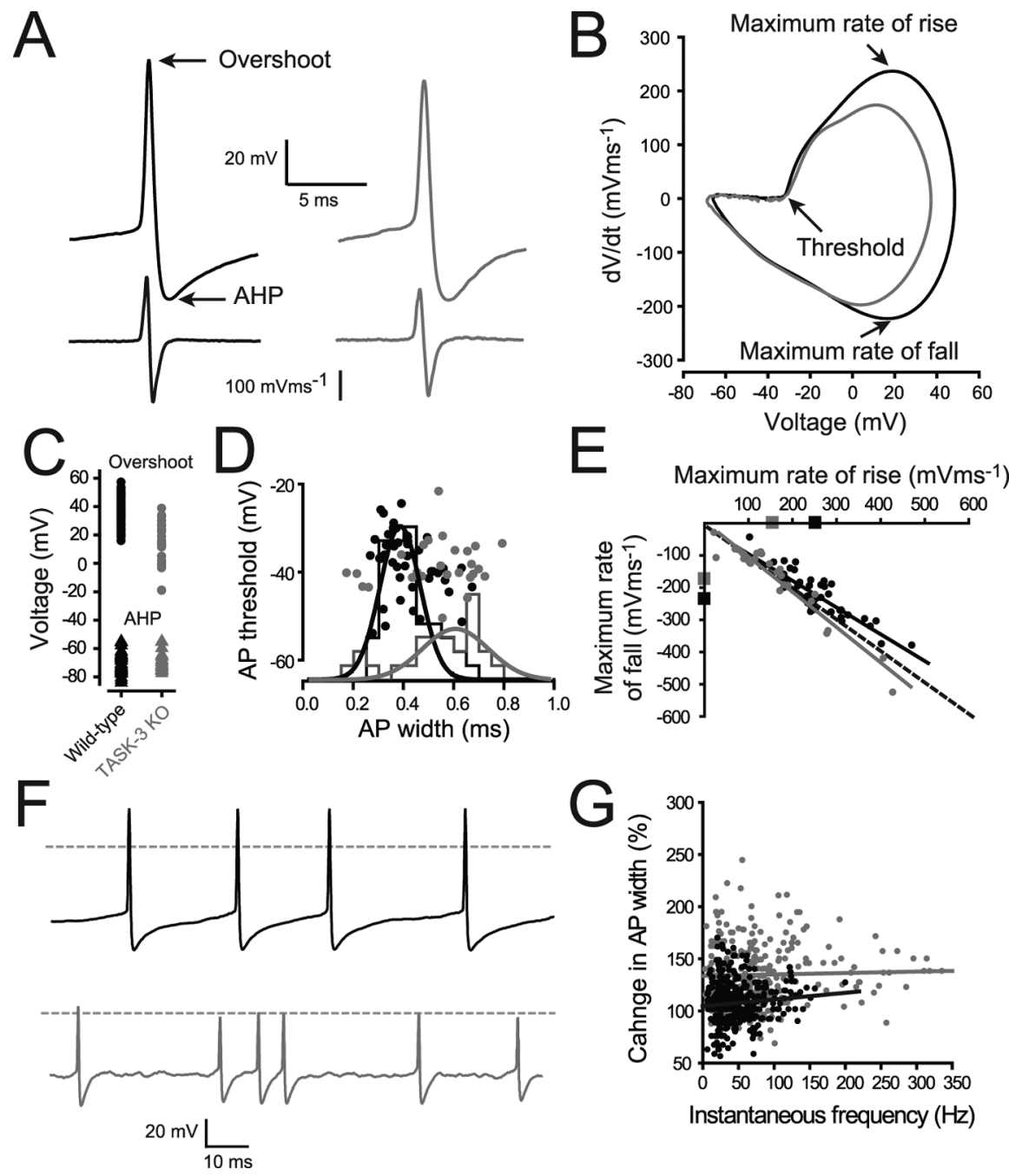
ings in a wild-type (black trace) and TASK-3 KO (gray trace) adult CGN. These two traces illustrate the reduction in AP overshoot, but unaltered AHP in recordings form TASK-3 KO adult CGNs. The first derivative for these two APs is shown in gray. $\boldsymbol{B}$, Phase plane plots of the APs shown in $A$, illustrating the similar AP threshold in the two waveforms, but reduced rate of AP rise and fall corresponding to a slower AP upstroke and repolarization in the TASK-3 KO CGN (red trace). C, Plots of the calculated AP overshoot and AHP in the wild-type (black circles; $n=49$ ) and TASK-3 KO (gray circles; $n=29$ ) populations. $D, A$ scatter plot of the AP threshold against AP width has been constructed for all wild type (black circles) and TASK-3 KO (gray circles) data. All-point histograms were then constructed from the AP width data, and the distributions for wild type and TASK-3 KO data were well described by a single Gaussian distribution (solid and gray lines, respectively). From these data, it is clear that the AP width in TASK-3 KO CGNs was broader than that found in the wild-type population. $\boldsymbol{E}$, Plot of the maximum rate of rise against the regressions for these two populations are shown as solid black and red lines. The dashed line indicates the predicted linear regression if both rates exhibit similar distributions. $F$, Continuous voltage records from a wild-type (top trace) and TASK-3 KO CGN (bottom trace) illustrating the pattern of APs elicited at threshold depolarization. G, Scatter plot illustrating the change in AP width at the observed instantaneous frequencies calculated in wild-type (black) and TASK-3 KO (gray) CGNs. The solid lines are the result of linear regression in each population.

frequencies during sustained depolarization was restored (Fig. $8 D$ ). Therefore, at suprathreshold depolarizations, the average accommodation index in TASK-3 KO CGNs was restored to a wild-type value of $1.02 \pm 0.14(n=7)$ after insertion of a $5 \mathrm{nS}$ nonlinear leak conductance. The speed of the dynamic clamp is highlighted in Figure $8 E$ in which we plot the altered current injection $\left(I_{\text {com }}\right)$ in response to the recorded change in membrane voltage $\left(V_{\mathrm{m}}\right)$. The speed of the dynamic current clamp is sufficient to respond during the fast APs that occur in adult CGNs. However, this speed is only attainable when implementing a simple GHK-type leak. When we attempted to introduce additional 


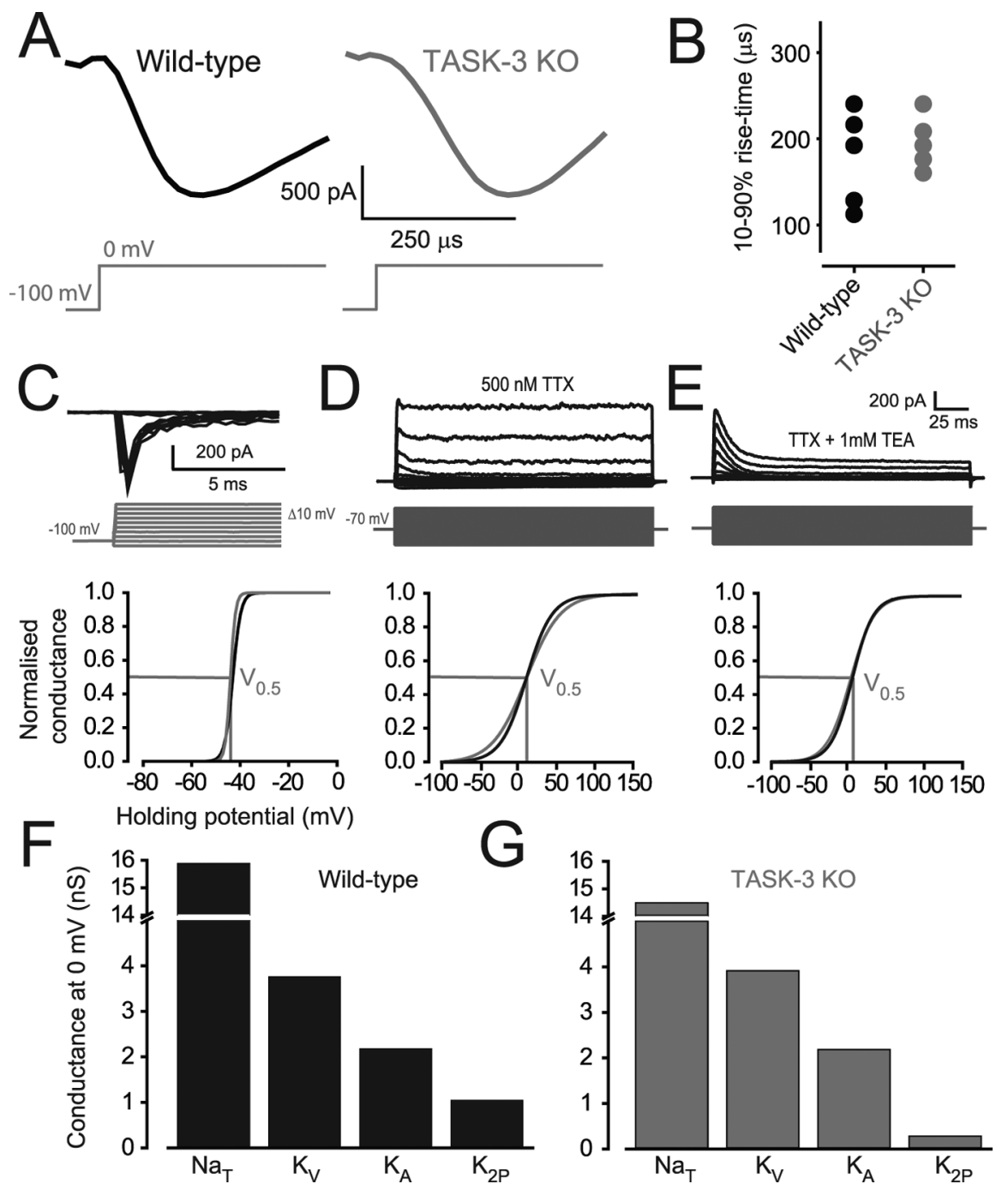

Figure 6. Functional properties of voltage-gated channels in adult CGNs. $\boldsymbol{A}$, Current traces showing the rising phase of a voltage-gated sodium conductance in response to a maximal activation elicited after a voltage step from -100 to $0 \mathrm{mV}$ (gray lines) recorded from a wild-type (black trace) and a TASK-3 KO (gray trace) adult CGN. $\boldsymbol{B}$, Plot of $10-90 \%$ rise times calculated from current traces of the type shown in $\boldsymbol{A}$ from wild-type (black circles; $n=6$ ) and TASK-3 KO (gray circles; $n=6$ ) adult CGNs. C, A series of voltage-step protocols (gray traces) were applied to examine the voltage dependence of sodium channel activation $\left(\mathrm{Na}_{\mathrm{T}}\right)$. A Boltzmann function was fitted to the peak conductance data for all cells examined to estimate both the $V_{0.5}$ and rate of activation. $\boldsymbol{D}$, Another series of voltage-step protocols (gray traces) examined the voltage dependence of activation for the sustained outward potassium currents $\left(K_{V}\right)$ recorded in the presence of $500 \mathrm{~nm}$ TTX, and once again a Boltzmann function was

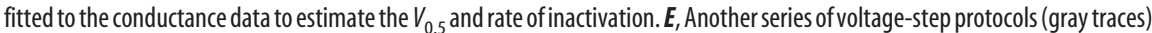
examined the voltage dependence of activation for the transient potassium currents $\left(\mathrm{K}_{\mathrm{A}}\right)$ recorded in the presence of $500 \mathrm{nM}$ TTX and $1 \mathrm{~mm} T E A$, and once again a Boltzmann function was fitted to the conductance data to estimate the $V_{0.5}$ and rate of inactivation. $\boldsymbol{F}$, Bar graph illustrating the relative contribution of the $\mathrm{Na}_{\mathrm{T}}, \mathrm{K}_{\mathrm{V}}, \mathrm{K}_{\mathrm{A}}$, and $\mathrm{K}_{2 \mathrm{P}}$ conductance in wild-type $\mathrm{C} \mathrm{GNs}$. The conductance of the voltage-gated currents was estimated at $0 \mathrm{mV}$ using the Boltzmann functions in $\boldsymbol{A}-\boldsymbol{C}$. The $\mathrm{K}_{\mathrm{V}}$ component represented the TEA-sensitive component of the steady-state outward current, whereas the $K_{2 P}$ component was estimated from the TEAinsensitive outward potassium currents shown in Figure 7. G, Same conventions as D but for TASK-3 KO CGNs. Note that the only component that has significantly changed is the $K_{2 P}$-like TEA-insensitive conductance reflecting the loss of TASK-3 channels.

parameters into the system, the iteration speed was severely compromised. Nevertheless, this rescue of function experiment demonstrates that the open rectification of a GHK-like leak conductance alone is sufficient to restore wild-type firing patterns to TASK-3 KO CGNs. This highlights an unappreciated role of a TASK-like conductance in the regulation of AP firing (see Discussion).

\section{Discussion}

$\mathrm{K}_{2 \mathrm{P}}$ channels can make a significant contribution to the resting potassium permeability of neuronal membranes (Millar et al.,
2000; Talley et al., 2000; Heurteaux et al., 2006). This becomes particularly apparent when G-protein activation results in their closure and the RMP is depolarized (Goldstein et al., 2001; Patel and Honoré, 2001; Mathie, 2007). In this study, we demonstrated that, in adult CGNs, TASK-3containing channels do hyperpolarize the RMP leading to reduced excitability at rest, but in addition this TASK-3-mediated conductance also becomes permissive for AP firing once the resting potassium leak has been overcome. We hypothesize that the increased potassium conductance provided by TASK-3 channels reduces the degree of depolarization block that VGSCs experience during excitatory drive. In addition, it is also possible that the voltagedependent increase in input conductance through TASK-3 channel opening can facilitate the removal of VGSCs from inactivation by reducing the membrane time constant. This represents an additional consequence of TASK-3 channel expression that has not been examined in previous studies.

TASK-1 removal did not alter the resting potassium permeability of adult CGNs and certainly did not alter any aspect of AP firing (Aller et al., 2005) (Fig. 3D). Nevertheless, there was an alteration in the modulation of the leak conductance in TASK-1 $\mathrm{KO} C \mathrm{CGN}$ by $\mathrm{pH}$, zinc, and ruthenium red consistent with the loss of TASK-1 (Aller et al., 2005). In this previous study, we postulated that TASK-1/TASK-3 heterodimers were replaced by TASK-3 homodimers in the TASK-1 KO CGNs. We suggested that the increased open probability of the TASK-3 homodimers compared with the wild-type heterodimer population (cf. Han et al., 2002) explained the normalization of the resting potassium permeability (Aller et al., 2005). The depolarized RMP of TASK-3 KO CGNs is consistent with this argument because any remaining TASK-1 homodimers would exhibit a low open probability relative to wild-type TASK-1/TASK-3 heterodimers. However, we cannot rule out that, in TASK-3 KO CGNs, TASK-1 protein is degraded, although TASK-1 mRNA is unaltered [cf. Jones et al. (1997) for an analogous situation with $\mathrm{GABA}_{\mathrm{A}}$ receptor subunits, in which, in the $\mathrm{GABA}_{\mathrm{A}}$ receptor $\alpha 6$ subunit knock-out, the $\delta$ subunit protein is degraded because it is an obligatory partner for $\alpha 6$, but $\delta$ mRNA is still present at wild-type levels]. It is also conceivable that, in adult CGNs at least, the TASK-1 protein serves as a modulatory or accessory subunit for TASK-3. Although there are few mouse brain regions in which TASK-1 expression predominates over TASK-3 as assessed by RNA levels (Linden et al., 2006), the majority of nuclei appear to have higher TASK-3 expression than TASK-1 (Fig. 1) [Linden et al. (2006), their Fig. 1; Aller et al. 
A

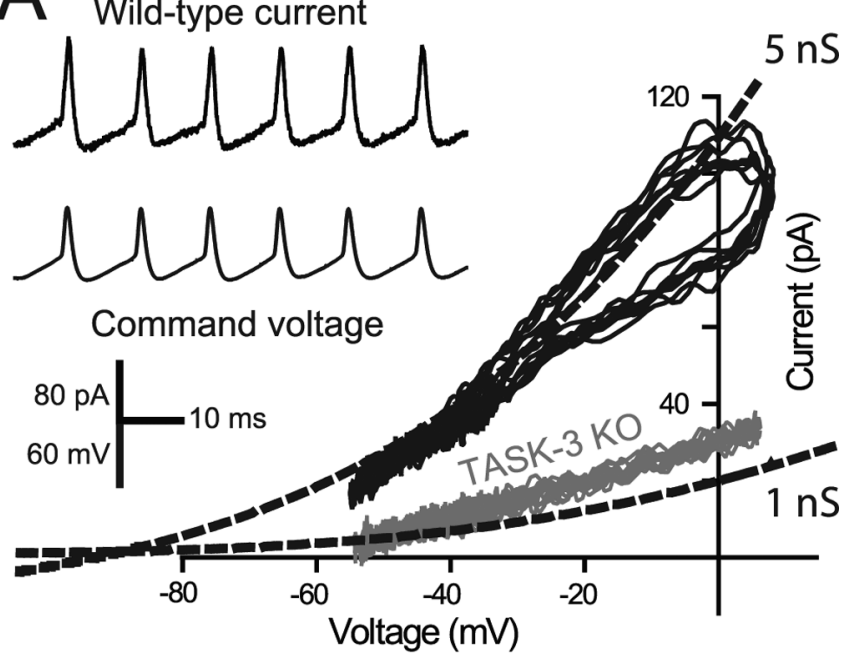

B mTASK-3 current

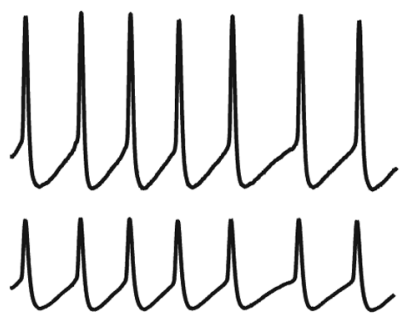

Command voltage

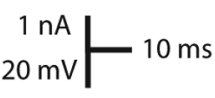

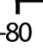

$10 \mathrm{~ms}$

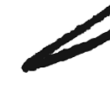

$-60$

Voltage $(\mathrm{mV})$

Figure 7. Response of a TASK-3-mediated conductance to sustained AP firing. $A$, Whole-cell voltage-clamp recordings were made from wild-type (black trace) and TASK-3 KO CGNs during which AP waveforms, recorded from a wild-type CGN, were used to control the command voltage of the patch-clamp amplifier. These recordings were also made in the presence of TTX, $T E A$, and 4-AP, and particular attention was paid to eliminating the resistive and capacitive errors associated with these recordings (see Materials and Methods). Current-voltage plots are shown for a wild-type (black) and TASK-3 KO (gray) CGN. Superimposed on this plot is the predicted GHK relationship for a 1 and $5 \mathrm{nS}$ potassium conductance (dashed lines). $\boldsymbol{B}$, Voltageclamp recording from tsA-201 cells after recombinant expression of TASK-3. The command voltage of the patch-clamp amplifier was once again controlled by AP waveforms previously recorded from an adult wild-type CGN. It is apparent that a TASK-3-mediated conductance is elicited by these AP waveforms. Moreover, when the current-voltage relationship of this response is plotted, a clear hysteresis loop can be observed similar to that previously seen in wild-type CGNs (compare with $\boldsymbol{A}$ ). However, this hysteresis loop was completely absent from untransfected cells (gray trace). The arrows indicate the rising and falling phase of the AP.

(2005), their Fig. 2]. At present, we know nothing about the assembly and subcellular targeting of TASK-1/TASK-3 channels, and our understanding of the cellular interactions that occur between these subunits will require the availability of good antibodies.

A surprising electrophysiological phenotype observed in this study is that AP accommodation is more pronounced in adult CGNs recorded from TASK-3 KO mice (Fig. 2). This was most apparent at suprathreshold levels of depolarization when complete AP failure was commonly observed by the end of a current
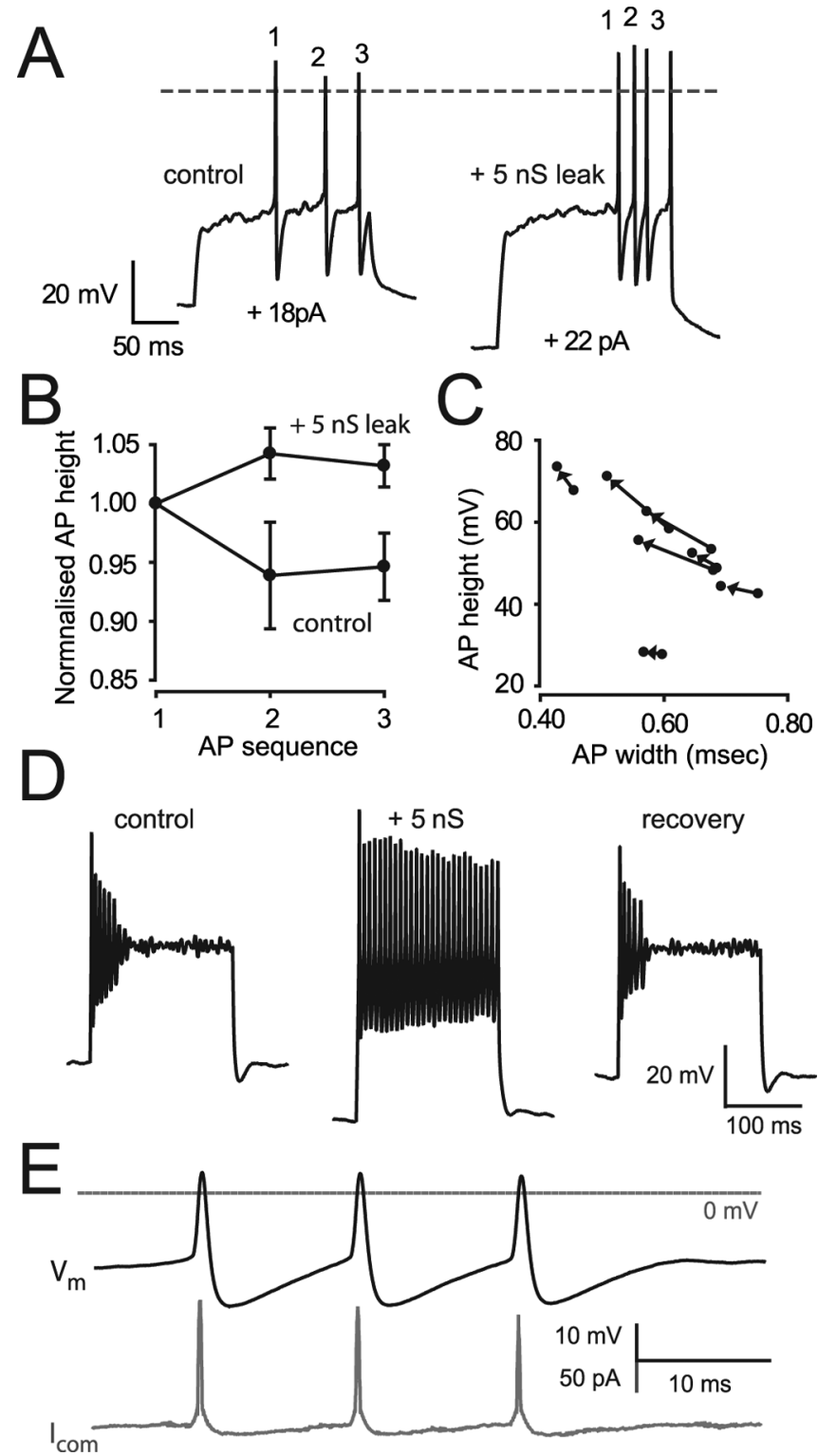

Figure 8. Rescue of AP accommodation by insertion of a nonlinear leak conductance in TASK-3 KO adult CGNs. $\boldsymbol{A}$, Results from a dynamic current-clamp experiment performed on a TASK-3 KO adult CGN at threshold levels of depolarization in the presence and absence of a $5 \mathrm{nS}$ GHK-type leak. Note that the RMP has hyperpolarized in the presence of a $5 \mathrm{nS}$ nonlinear leak, and therefore, more current is required to reach threshold. $\boldsymbol{B}$, Quantification of the AP height before and during injection of a $5 \mathrm{nS}$ nonlinear leak in TASK-3 KO adult CGNs. The AP height has been normalized to the first AP in the burst. Error bars indicate SEM. C, Plot of the AP height and $\mathrm{AP}$ width in each experiment in which a $5 \mathrm{nS}$ nonlinear leak has been inserted. The arrows link the estimated values in each experiment before and during insertion of the leak conductance. $\boldsymbol{D}$, Results from a dynamic current-clamp experiment performed on a TASK-3 KO CGN that exhibited complete AP accommodation during a suprathreshold depolarization. In the presence of a $5 \mathrm{nS}$ nonlinear leak conductance waveform, we restored the ability of this CGN to fire during sustained depolarization. The middle trace was performed with the dynamic current-clamp waveform implemented, whereas the two traces on either side were obtained immediately before and after the waveform was present. Note how the RMP hyperpolarizes in response to the nonlinear leak conductance. $E$, Illustration of how the recorded voltage (black trace; $V_{\mathrm{m}}$ ) influences the injected current (gray trace; $I_{\text {com }}$ ) when the dynamic current-clamp waveform is implemented with a 5 nS GHK-type leak.

pulse (Fig. 3). During suprathreshold current injection in TASK-3 KO recordings, the reduced input conductance of CGNs results in a greater level of depolarization leading to increased VGSC inactivation. This highlights the physiological importance 
of a TASK-3-mediated conductance in limiting voltagedependent inactivation of VGSCs. The accommodation phenotype is not greatly influenced by steady-state inactivation of VGSCs (Fig. 4) and does not appear to involve biophysical alterations in the VGSCs themselves (Fig. 6). We postulate that the ability of a TASK-mediated conductance to limit AP accommodation at threshold voltages could relate to the nonlinear behavior of the membrane. The increased input conductance that occurs during the AP will reduce the membrane time constant, leading to faster recovery of VGSCs from inactivation. Changes in the membrane time constant also explain the briefer AP width in wild-type CGNs (Fig. 5). This is most notable during the AP upstroke when conventional voltage-gated potassium channels have little influence, but the increased membrane conductance provided by TASK channels contributes significantly to the membrane time constant.

We previously suggested that open rectification of a TASKmediated conductance contributes to the voltage dependence of the input conductance described in adult CGNs (Brickley et al., 2001; Cathala et al., 2003; Aller et al., 2005). In support of this argument, the dynamic current-clamp experiments demonstrated that a GHK-type nonlinear conductance on its own was sufficient to restore wild-type firing to CGNs recorded from TASK-3 KO mice both at threshold (Fig. $8 \mathrm{~A}$ ) and suprathreshold (Fig. $8 D$ ) levels of depolarization. Insertion of a nonlinear leak conductance also altered AP width and height in the TASK-3 KO CGN recordings (Fig. 8C), consistent with our postulated role of TASK-3 channels in the wild type. However, as shown during AP injection experiments (Fig. 7), we also saw some hysteresis of the TASK-3-mediated conductance between the rising and falling phase of the AP waveform, consistent with a modest voltage dependence of channel opening for TASK-3 (Rajan et al., 2000; Meadows and Randall, 2001). Addition of these voltagedependent parameters was not possible using our dynamic current-clamp configuration (because of insufficient processing power), but we would predict that these parameters would further accentuate the ability of a TASK-mediated conductance to support sustained AP firing.

The mossy fiber excitatory input to CGNs can maintain transmitter release at frequencies of up to $300 \mathrm{~Hz}$ (Saviane and Silver, 2006), and adult CGNs respond to continued depolarization with nonaccommodating AP firing of $>200 \mathrm{~Hz}$, both in vitro (Brickley et al., 2001) and in vivo (Chadderton et al., 2004; Jorntell and Ekerot, 2006). Based on our findings, CGNs lacking TASK-3 will be compromised in their ability to support high-frequency firing during prolonged mossy fiber excitation in vivo. However, because TASK-3 KO mice have no ataxic phenotype, it is likely that there has been some resetting of the system at the neuronal network level. This comes as no surprise: the cerebellum is remarkably robust to many disruptions that were anticipated to compromise motor function. For example, genetically deleting extrasynaptic $\mathrm{GABA}_{\mathrm{A}}$ receptors that give rise to tonic inhibition in CGNs produces no motor phenotype (Jones et al., 1997; Brickley et al., 2001). Similarly, only mild motor impairments are found when the Na channel gene Scn8a (Nav1.6) is deleted selectively from CGNs (Levin et al., 2006); and even selective loss of synaptic $\mathrm{GABA}_{\mathrm{A}}$ receptors from Purkinje cells, so that feedforward inhibition is removed, does not result in ataxia (Wulff et al., 2007). The ability of the cerebellum to compensate for chronic removal of a specific conductance is further demonstrated by the study by Watanabe et al. (1998) in which genetic ablation of Golgi cell inhibitory input to CGNs initially resulted in a motor defect that then reduced in severity over time. In contrast, we would predict that a selective chemical antagonist (not yet existing) of TASK-3 channels would immediately compromise motor performance (cf. Wulff and Wisden, 2005; Wulff et al., 2007). Nevertheless, at the cellular level, the genetic approach has given an informative insight into TASK-3 channel function, highlighting some unappreciated contributions that this conductance makes to the biophysical properties of CGNs.

This ability of a potassium conductance to allow highfrequency firing is usually associated with $\mathrm{K}_{\mathrm{V}} 3$ channels (Brew and Forsythe, 1995) (for review, see Rudy and McBain, 2001; Bean, 2007). Our dynamic current-clamp experiments demonstrate that a TASK-like conductance can facilitate AP firing similarly to that observed when a more complicated $\mathrm{K}_{\mathrm{V}} 3$-like conductance was reintroduced into fast spiking interneurons (Lien and Jonas, 2003). This additional feature of a TASK-3 conductance highlights how regulation of TASK channels, such as through the activation of G-protein-coupled receptors, could allow neuronal excitability to be fine-tuned because these channels both select and sustain appropriate synaptic inputs. So, the hyperpolarized RMP and increased input conductance at rest will filter excitatory drive (by making EPSPs smaller and briefer) (cf. Cathala et al., 2003), increasing the requirement for closer timing of synaptic inputs before AP threshold is reached. However, once AP threshold is reached, the TASK-3 conductance will contribute to sustained AP firing by reducing the degree of sodium channel inactivation.

Because the TASK-3 gene expresses in other neurons that require sustained high-frequency AP firing (e.g., parvalbuminpositive hippocampal interneurons) (Torborg et al., 2006), it could be that the ability of a TASK-mediated conductance to sustain high-frequency firing is more general. Indeed, a potassium leak conductance with a pharmacological profile reminiscent of TASK-3 channels occurs in the myelinated axons of motor neurons in Xenopus laevis (Koh et al., 1992). It is possible that a TASK-3 conductance in combination with VGSCs is sufficient to support high-frequency firing, and it would be interesting to directly examine the contribution these potassium leak channels make to AP generation in mammalian myelinated axons.

\section{References}

Akemann W, Knöpfel T (2006) Interaction of Kv3 potassium channels and resurgent sodium current influences the rate of spontaneous firing of Purkinje neurons. J Neurosci 26:4602-4612.

Aller MI, Veale E, Linden AM, Sandu C, Schwaninger M, Evans L, Korpi ER, Mathie A, Wisden W, Brickley SG (2005) Modifying the subunit composition of TASK channels alters the modulation of a leak conductance in cerebellar granule neurons and is associated with impaired motor performance. J Neurosci 25:11455-11467.

Bean BP (2007) The action potential in mammalian central neurons. Nat Rev Neurosci 8:451-465.

Berg AP, Bayliss DA (2007) Striatal cholinergic interneurons express a receptor-insensitive homomeric TASK-3-like background $\mathrm{K}^{+}$current. J Neurophysiol 97:1546-1552.

Brew H, Forsythe ID (1995) Two voltage-dependent $\mathrm{K}^{+}$conductances with complementary functions in postsynaptic integration at a central auditory synapse. J Neurosci 15:8011-8022.

Brickley SG, Revilla V, Cull-Candy SG, Wisden W, Farrant M (2001) Adaptive regulation of neuronal excitability by a voltage-independent potassium conductance. Nature 409:88-92.

Cathala L, Brickley S, Cull-Candy S, Farrant M (2003) Maturation of EPSCs and intrinsic membrane properties enhances precision at a cerebellar synapse. J Neurosci 23:6074-6085.

Chadderton P, Margrie TW, Hausser M (2004) Integration of quanta in cerebellar granule cells during sensory processing. Nature 428:856-860.

Chapman CG, Meadows HJ, Godden RJ, Campbell DA, Duckworth M, Kelsell RE, Murdock PR, Randall AD, Rennie GI, Gloger IS (2000) Clon- 
ing, localisation and functional expression of a novel human, cerebellum specific, two pore domain potassium channel. Brain Res Mol Brain Res 82:74-83.

Chemin J, Girard C, Duprat F, Lesage F, Romey G, Lazdunski M (2003) Mechanisms underlying excitatory effects of group I metabotropic glutamate receptors via inhibition of $2 \mathrm{P}$ domain $\mathrm{K}^{+}$channels. EMBO J 22:5403-5411.

Cole KS (1949) Some physical aspects of bioelectric phenomena. Proc Natl Acad Sci USA 35:558-566.

Cope DW, Wulff P, Oberto A, Aller MI, Capogna M, Ferraguti F, Halbsguth C, Hoeger H, Jolin HE, Jones A, McKenzie AN, Ogris W, Poeltl A, Sinkkonen ST, Vekovischeva OY, Korpi ER, Sieghart W, Sigel E, Somogyi P, Wisden W (2004) Abolition of zolpidem sensitivity in mice with a point mutation in the $\mathrm{GABA}_{\mathrm{A}}$ receptor $\gamma 2$ subunit. Neuropharmacology 47:17-34.

D’Angelo E, De Filippi G, Rossi P, Taglietti V (1998) Ionic mechanism of electroresponsiveness in cerebellar granule cells implicates the action of a persistent sodium current. J Neurophysiol 80:493-503.

D’Angelo E, Nieus T, Maffei A, Armano S, Rossi P, Taglietti V, Fontana A, Naldi G (2001) Theta-frequency bursting and resonance in cerebellar granule cells: experimental evidence and modeling of a slow K-dependent mechanism. J Neurosci 21:759-770.

Goldman DE (1943) Potential, impedance, and rectification in membranes. J Gen Physiol 27:7-60.

Goldstein SA, Bockenhauer D, O’Kelly I, Zilberberg N (2001) Potassium leak channels and the KCNK family of two-P-domain subunits. Nat Rev Neurosci 2:175-184.

Gu W, Schlichthorl G, Hirsch JR, Engels H, Karschin C, Karschin A, Derst C, Steinlein OK, Daut J (2002) Expression pattern and functional characteristics of two novel splice variants of the two-pore-domain potassium channel TREK-2. J Physiol (Lond) 539:657-668.

Han J, Truell J, Gnatenco C, Kim D (2002) Characterization of four types of background potassium channels in rat cerebellar granule neurons. J Physiol (Lond) 542:431-444.

Heurteaux C, Lucas G, Guy N, El Yacoubi M, Thummler S, Peng XD, Noble F, Blondeau N, Widmann C, Borsotto M, Gobbi G, Vaugeois JM, Debonnel G, Lazdunski M (2006) Deletion of the background potassium channel TREK-1 results in a depression-resistant phenotype. Nat Neurosci 9:1134-1141.

Hodgkin AL, Katz B (1949) The effect of sodium ions on the electrical activity of the giant axon of the squid. J Physiol (Lond) 108:37-77.

Jones A, Korpi ER, McKernan RM, Pelz R, Nusser Z, Makela R, Mellor JR, Pollard S, Bahn S, Stephenson FA, Randall AD, Sieghart W, Somogyi P, Smith AJ, Wisden W (1997) Ligand-gated ion channel subunit partnerships: $\mathrm{GABA}_{\mathrm{A}}$ receptor $\alpha 6$ subunit gene inactivation inhibits $\delta$ subunit expression. J Neurosci 17:1350-1362.

Jorntell H, Ekerot CF (2006) Properties of somatosensory synaptic integration in cerebellar granule cells in vivo. J Neurosci 26:11786-11797.

Kang D, Han J, Talley EM, Bayliss DA, Kim D (2004) Functional expression of TASK-1/TASK-3 heteromers in cerebellar granule cells. J Physiol (Lond) 554:64-77.

Karschin C, Wischmeyer E, Preisig-Muller R, Rajan S, Derst C, Grzeschik KH, Daut J, Karschin A (2001) Expression pattern in brain of TASK-1, TASK-3, and a tandem pore domain $\mathrm{K}^{+}$channel subunit, TASK-5, associated with the central auditory nervous system. Mol Cell Neurosci $18: 632-648$.

Kim Y, Bang H, Kim D (2000) TASK-3, a new member of the tandem pore $\mathrm{K}^{+}$channel family. J Biol Chem 275:9340-9347.

Koh DS, Jonas P, Brau ME, Vogel W (1992) A TEA-insensitive flickering potassium channel active around the resting potential in myelinated nerve. J Membr Biol 130:149-162.

Kullmann PH, Wheeler DK, Beacom J, Horn JP (2004) Implementation of a fast 16-bit dynamic clamp using LabVIEW-RT. J Neurophysiol 91:542-554.

Levin SI, Khaliq ZM, Aman TK, Grieco TM, Kearney JA, Raman IM, Meisler MH (2006) Impaired motor function in mice with cell-specific knockout of sodium channel Scn8a (NaV1.6) in cerebellar purkinje neurons and granule cells. J Neurophysiol 96:785-793.
Lien CC, Jonas P (2003) Kv3 potassium conductance is necessary and kinetically optimized for high-frequency action potential generation in hippocampal interneurons. J Neurosci 23:2058-2068.

Linden AM, Aller MI, Leppa E, Vekovischeva O, Aitta-Aho T, Veale EL, Mathie A, Rosenberg P, Wisden W, Korpi ER (2006) The in vivo contributions of TASK-1-containing channels to the actions of inhalation anesthetics, the alpha(2) adrenergic sedative dexmedetomidine, and cannabinoid agonists. J Pharmacol Exp Ther 317:615-626.

Mathie A (2007) Neuronal two-pore-domain potassium channels and their regulation by G protein-coupled receptors. J Physiol (Lond) 578:377-385.

Meadows HJ, Randall AD (2001) Functional characterisation of human TASK-3, an acid-sensitive two-pore domain potassium channel. Neuropharmacology 40:551-559.

Meuth SG, Aller MI, Munsch T, Schuhmacher T, Seidenbecher T, Meuth P, Kleinschnitz C, Pape HC, Wiendl H, Wisden W, Budde T (2006) The contribution of TWIK-related acid-sensitive $\mathrm{K}+$-containing channels to the function of dorsal lateral geniculate thalamocortical relay neurons. Mol Pharmacol 69:1468-1476.

Millar JA, Barratt L, Southan AP, Page KM, Fyffe RE, Robertson B, Mathie A (2000) A functional role for the two-pore domain potassium channel TASK-1 in cerebellar granule neurons. Proc Natl Acad Sci USA 97:3614-3618.

Patel AJ, Honoré E (2001) Properties and modulation of mammalian 2P domain $\mathrm{K}^{+}$channels. Trends Neurosci 24:339-346.

Rajan S, Wischmeyer E, Xin Liu G, Preisig-Muller R, Daut J, Karschin A, Derst C (2000) TASK-3, a novel tandem pore domain acid-sensitive $\mathrm{K}^{+}$channel: an extracellular histidine as $\mathrm{pH}$ sensor. J Biol Chem 275:16650-16657.

Rajan S, Wischmeyer E, Karschin C, Preisig-Muller R, Grzeschik KH, Daut J, Karschin A, Derst C (2001) THIK-1 and THIK-2, a novel subfamily of tandem pore domain $\mathrm{K}^{+}$channels. J Biol Chem 276:7302-7311.

Rudy B, McBain CJ (2001) Kv3 channels: voltage-gated $\mathrm{K}^{+}$channels designed for high-frequency repetitive firing. Trends Neurosci 24:517-526.

Saviane C, Silver RA (2006) Fast vesicle reloading and a large pool sustain high bandwidth transmission at a central synapse. Nature 439:983-987.

Talley EM, Lei Q, Sirois JE, Bayliss DA (2000) TASK-1, a two-pore domain $\mathrm{K}^{+}$channel, is modulated by multiple neurotransmitters in motoneurons. Neuron 25:399-410.

Talley EM, Solorzano G, Lei Q, Kim D, Bayliss DA (2001) CNS distribution of members of the two-pore-domain (KCNK) potassium channel family. J Neurosci 21:7491-7505.

Torborg CL, Berg AP, Jeffries BW, Bayliss DA, McBain CJ (2006) TASK-like conductances are present within hippocampal CA1 stratum oriens interneuron subpopulations. J Neurosci 26:7362-7367.

Vega-Saenz De Miera E, Lau DH, Zhadina M, Pountney D, Coetzee WA, Rudy B (2001) KT3.2 and KT3.3, two novel human two-pore ${ }^{+}$channels closely related to TASK-1. J Neurophsyiol 86:130-142.

Watanabe D, Inokawa H, Hashimoto K, Suzuki N, Kano M, Shigemoto R, Hirano T, Toyama K, Kaneko S, Yokoi M, Moriyoshi K, Suzuki M, Kobayashi K, Nagatsu T, Kreitman RJ, Pastan I, Nakanishi S (1998) Ablation of cerebellar Golgi cells disrupts synaptic integration involving GABA inhibition and NMDA receptor activation in motor coordination. Cell 95:17-27.

Wisden W, Morris BJ (1994) In situ hybridization with synthetic oligonucleotide probes. In: In situ hybridization protocols for the brain (Wisden W, Morris BJ, eds), pp 9-43. London: Academic.

Wulff P, Wisden W (2005) Dissecting neural circuitry by combining genetics and pharmacology. Trends Neurosci 28:44-50.

Wulff P, Goetz T, Leppä E, Linden AM, Renzi M, Swinny JD, Vekovischeva OY, Sieghart W, Somogyi P, Korpi ER, Farrant M, Wisden W (2007) From synapse to behaviour: rapid modulation of defined neuronal populations through engineered $\mathrm{GABA}_{\mathrm{A}}$ receptors. Nat Neurosci 10:923-929.

Zanzouri M, Lauritzen I, Duprat F, Mazzuca M, Lesage F, Lazdunski M, Patel A (2006) Membrane potential-regulated transcription of the resting $\mathrm{K}^{+}$ conductance TASK-3 via the calcineurin pathway. J Biol Chem 281:28910-28918. 